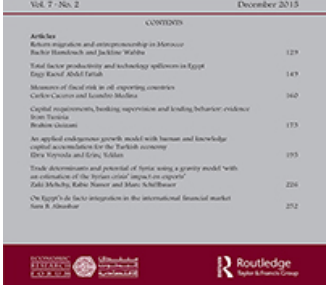

\title{
An applied endogenous growth model with human and knowledge capital accumulation for the Turkish economy
}

\section{Ebru Voyvoda \& Erinç Yeldan}

To cite this article: Ebru Voyvoda \& Erinç Yeldan (2015) An applied endogenous growth model with human and knowledge capital accumulation for the Turkish economy, Middle East Development Journal, 7:2, 195-225, DOI: 10.1080/17938120.2015.1072698

To link to this article: https://doi.org/10.1080/17938120.2015.1072698

曲 Published online: 02 Oct 2015.

Submit your article to this journal

Џ Article views: 69

View Crossmark data $\complement$ 


\section{An applied endogenous growth model with human and knowledge capital accumulation for the Turkish economy}

Ebru Voyvoda $^{\text {a* }}$ and Erinç Yeldan ${ }^{\mathrm{b}}$

${ }^{a}$ Department of Economics, Middle East Technical University, Ankara, Turkey; ${ }^{b}$ Department of Economics, I.D. Bilkent University, Ankara, Turkey

(Received 17 September 2013; accepted 31 May 2015)

We analytically investigate and assess the interactions between knowledge-driven growth, acquisition of human capital, and the role of strategic public policy for the Turkish economy within the context of a general equilibrium model. The model aims to investigate the public policies toward fostering the development of human capital (such as investments in education and learning) and those at enhancing total factor productivity through investments in physical capital and innovation (such as subsidies to R\&D), and to study the impact of various public policies on patterns of growth, along with their likely consequences from the points of view of capital accumulation, income distribution, social welfare and economic efficiency for the Turkish economy. With the aid of the model, we seek for analytical answers to the following question: for a government constrained with its budgetary requirements, which type of public subsidiziation policies is more conducive for enhancing growth and social welfare: promotion of human capital formation through subsidies to education expenditures, or promotion of new $R \& D$ formation through subsidies to $R \& D$ investment expenditures? According to the model findings, a single-handed strategy of only subsidizing education expenditures to promote human capital formation falls short of achieving desirable growth performance in the medium to long run. Under the policy of human capital formation promotion, expected growth and welfare results are weak in the medium-to-long run unless increased human capital can upgrade the number of research personnel employed in the R\&D development sector. Under these observations, it can be argued that the public policy should be directed to $\mathrm{R} \& \mathrm{D}$ promotion in the medium-to-long run to complement an education promotion program to sustain human capital formation.

Keywords: endogenous growth; human capital; R\&D; general equilibrium; Turkish economy; public policy for education and R\&D

JEL Classification Codes: O41; O51; O30; O15; H20

\section{Introduction}

The Turkish economy is on a slowing growth path. Observations reveal that the average annual rate of real growth had receeded from $4.5 \%$ over the $1980 \mathrm{~s}$ to $4.1 \%$ over the $1990 \mathrm{~s}$, and to $4.0 \%$ in 2000-2014. Needless to assert, a major factor behind the slowdown is the ongoing great recession at the global scale. Nevertheless, many attributes remain unique to Turkey: delayed education institutionalization and

*Corresponding author. Email: voyvoda@metu.edu.tr 
lagging human capital investments, low rates of Research and Development (R\&D) along with a low R\&D investment share of the GDP, low rate of commercialization of basic research output; along with structural macroeconomic imbalances revealed in the severe drop of national savings and a consequent widening of the current account deficit.

In their historical analysis of the long-term patterns of economic growth of Turkey, Altuğ, Filiztekin, and Pamuk (2008) argue that the problem stems from the slow growth of capital expansion, while others attribute the slowdown to the falling rates of total factor productivity (TFP) growth (see, e.g. Filiztekin, 2001; Taymaz, Voyvoda, \& Y1lmaz, 2008; Yeldan \& Güneş, 2014). A further major line of research approaches the problem in the wider context of the middle-income trap, and argues that for Turkey, the relatively easy phases of early take-off based on transfer of cheap labor from rural to urban industrial centers has already been exhausted, and that from now on sources of growth ought to be generated from institutional and technological innovations (Öz, 2012; Özsan, Taşçıand, \& Akpınar, 2011; Yeldan, Taşçı, Voyvoda, \& Özsan, 2013).

Evidently, one of the main reasons why Turkey, as a middle-income country, cannot make it to the high-income group of countries is due to its low labor productivity which, in turn, stems from the low level of skill acquisition of its labor force. Despite the continued progression, average duration of schooling in Turkey stands at 6.7 years (less than the middle school diploma on average, see OECD, 2013a; Yeldan et al., 2013). The OECD (2013a) Education report reveals furthermore that a significant share of the Turkish young (ages 15-29) is observed to be inactive (neither in the labor market nor in education). Turkey maintains only $32 \%$ of its young population in education, while this ratio averages $47 \%$ among the OECD member countries.

Thus, Turkey is at a crossroads: on the one hand, it has to allocate a higher share of its national income to R\&D and to enhancing its human capital formation; and on the other hand, it has to maintain its overall macroeconomic balances and the intertemporal budget constraints for sustainability. This paper attempts to shed light into these questions within the discipline of macroeconomic equilibrium and intertemporal dynamics, given recent advances in modern growth theory.

Theory suggests that economic growth that solely depends on the accumulation of physical capital is unsustainable. This fact, which was first put through by Solow (1956), asserts that the most important obstacle against capital accumulation is diminishing returns. As a matter of fact, the new economic growth literature indicates that there exist strong linkages between growth of national income and expenditures on education, knowledge (R\&D), and other social infrastructures. Expenditures on education (investing in human capital) directly elevate the efficiency of the labor force, and provide significant externalities for growth. Additionally, R\&D activities conducted by both private and public sectors raise the available knowledge level and elicit capital accumulation. Thus, economic growth is fed by two sources which nourish each other: Education and R\&D capital accumulation. Both practices have cross spillover effects onto the other.

These observations led to the construction of economic models which allow for limitless growth of per capita income, and in which long-run performance depends on structural parameters and domestic and foreign fiscal policies. Some theories consider capital accumulation, which became a broader concept with the inclusion of human capital, as the engine of growth (Jones \& Manuelli, 1990; King \& Rebelo, 
1993; Rebelo, 1991). Another approach attributes a leading role to externalities in the growth process. Each firm's physical (Arrow, 1962) and human (Lucas, 1988) capital investment unintendedly contributes to the productivity of other firms' capitals. Pioneered by Romer (1990, 1992), Grossman and Helpman (1991, 1994), Aghion and Howitt (1998), a third approach focuses on the effect of human capital on economic growth by triggering technological development and adoption of new technologies. The new growth literature that follows the paths of the above-mentioned literature, developed models in which private industrial development, capital variety production, and technical skill dispersion lead to growth, depending on the importance of knowledge-led economic conditions.

Clearly, the potential determinants of long-run growth are numerous and a single paradigm based on the experience of a selected number of countries cannot capture all of the long-run dynamics of the history of real-world economies. For example, in their review of the growth experience of the East Asian countries, Stiglitz and Uy (1996) suggest that the determinants of growth are generally caused by a host of market failures that vary by country and by the level of development. This view implies that models focusing on a single or narrowly based determinant of growth are unlikely to explain the experience of a large number of countries. Keeping in mind the gulf that still appears to exist between the various theories of growth and the available empirical evidence to support one category of theory over another, it is nevertheless possible to empirically explore and contrast the effects of human capital formation, technological spillovers and the production of capital varieties on growth. In this context, attention can also be focused on the extent to which a decentralized market economy provides adequate incentives for the accumulation of production technology, and how variations in economic structures, institutions, and public policies might translate into different rates of productivity gains.

The main purpose of this study is to take stock of this broad literature and to analytically investigate and assess the interactions between knowledge-driven growth, acquisition of human capital, and the role of strategic public policy for the Turkish economy within the context of a general equilibrium model. The main analytical rationale of the model rests on the complementary relationships between government expenditures on education and other knowledge capital investment, and private expenditures on R\&D and knowledge capital investment with a direct intent to provide a decomposition of growth dynamics for the Turkish economy. We investigate two alternative public policies aimed at fostering the development of human capital (such as investments in education and learning) and those at enhancing TFP through investments in innovation (such as subsidies to R\&D), and study the impact of various public policies on patterns of growth, along with their likely consequences from the points of view of per capita income growth, social welfare, burden to the government budget and economic efficiency.

In line with these objectives, the underlying model of the study is based on the analytical setup of two main approaches of Lucas (1988) and Romer (1990). Both analytical approaches link growth to different individual elements and beyond that set up economic activities using a representative consumer/household. The model used here aims to examine Turkey as a developing country by preserving its main characteristics and macroeconomic structure using real data.

The analytical model simulates the 'production - creation of income - and demand generation' components of the national economy under market constraints in an 
applied general equilibrium context. In the model, four production industries, labor markets that consist of formal (human capital) and informal labor force, and public sector balances are decomposed by means of algebraic equations. The production process is portrayed as an augmented Cobb-Douglas type of production function that utilizes both skilled (human capital) and unskilled labor and physical capital varieties. Industrial production increases with the accumulation of intermediate capital varieties. Intermediate capital varieties are designed through knowledge capital (R\&D). Knowledge capital investments are performed by oligopolistic (Shumpeterian) entities and oligopolistic profits are used to finance the upfront R\&D investments. In the meantime, fixed costs enable increasing returns to scale in the expansion of capital varieties, and allow the growth process to be sustained endogenously.

Furthermore, the accumulation of knowledge capital depends on the production of human capital. Human capital is solved endogenously by dynamics of inter-household, intertemporal consumption optimization behavior, and is nourished by externality effects of public expenditures. Thus, three main forces that provide economic growth emerge: knowledge capital accumulation, human capital accumulation, and accumulation of capital varieties. While all of these depend on rational optimization behavior of private investors under market constraints, they are also affected by the medium/long-run expenditures of the government to provide stimulus to R\&D and education (human capital) investments. Thus, the macroeconomic general equilibrium model used in this study has a unique approach that combines the optimization elements of the private sector and strategic growth objectives of the government.

Static general equilibrium models were built previously to study different kinds of topics in the Turkish economy literature. Dervis, deMelo, and Robinson (1982), Lewis (1992), Yeldan (1997, 1998), Diao, Roe, and Yeldan (1999), Voyvoda and Yeldan (2005), and Agénor, Tarp-Jensen, Verghis, and Yeldan (2007) are some examples. Lewis (1992), Yeldan (1997), and Agénor et al. (2007) are composite models which also contain financial sectors besides real sectors, and focus more on taxation and trade. Cass-Kopmans-Ramsey type dynamic general equilibrium models based on consumption smoothing for Turkish economy are very few. Diao et al. (1999) studied fiscal cum trade policy alternatives for the Turkish economy, where Voyvoda and Yeldan (2005) analyzed policy alternatives for sustainability of public debt and the inter-generational wealth effects in an endogenous growth modeling context.

The remaining pages of the study are organized in five sections. In the second section, we present R\&D and human capital data, and discuss characteristics of the growth path for Turkey. The analytical and algebraic set up of the model is presented in the third section, while policy analyses are conducted in the fourth section. In the fifth section, we summarize the main findings of the study and conclude. The data set and calibration strategy of the algebraic model are introduced in a separate appendix section in deeper detail.

\section{Main characteristics of $R \& D$ and human capital accumulation in Turkish economy}

Turkey displays typical developing country characteristics from the perspective of R\&D investment activity. According to the Tenth Five-Year Development Plan documentation published by the Ministry of Development, the proportion of Gross Domestic Expenditures on R\&D (GERD) to GDP was $0.95 \%$ in 2013. In contrast, the OECD data document that the EU-28 average was 1.92\% (OECD, 2013b). The 
share of $R \& D$ expenditures performed by the private sector to total R\&D expenditures was $33.8 \%$ in 2005 , and reached $47.4 \%$ in 2013. Considering the EU-28 average, this ratio was reportedly $63.7 \%$ in that year (Table 1). Data reveal that $0.83 \%$ of the aggregate GERD is financed from abroad in Turkey. Interestingly, this ratio is even lower in the leading countries (Japan: 0.52\%; Korea: 0.30\%). In attracting financing from abroad for GERD, Israel is the leading economy with $48.78 \%$, followed by the Czech Republic (27.15\%), Ireland (21\%), and UK (20\%).

According to OECD data, in 2013 total labor engaged in R\&D activities in Turkey was 112.9 thousands and constituted $0.44 \%$ of the total civilian employment, while the same ratio was $1.21 \%$ in EU-28 (Table 2). According to this criterion, Turkey ranks second from the bottom (in front of Chile) among our sample of 34 OECD member countries. Thus, we can conclude that although full-time equivalent R\&D labor force is steadily increasing in Turkey, it is still behind desirable levels. In fulltime equivalent values, in $2005,30.4 \%$ of the R\&D labor employment was generated by the private sector, and it reached $41.8 \%$ in 2013 . When we take a look at the EU-28, we observe that $52 \%$ of the R\&D employment was created by the private sector; $47.8 \%$ of total R\&D personnel are composed of higher education researchers in Turkey, while this number averages $38.6 \%$ in the EU-28. Results of the Innovation Survey (20062008) as conducted by the Turkish Statistical Institute (TurkStat, 2008) indicate that $37.1 \%$ of the enterprises that employ more than 10 workers were engaged in innovation activities. The same data source reveals that innovation activities tend to grow in direct proportion to the scale of the enterprises, $33.8 \%$ for enterprises that employ between 10 and 49 workers; $43.7 \%$ for enterprises that have between 50 and 29 workers; and $54.4 \%$ for enterprises that have more than 250 workers stated that they were engaged in innovation activities.

Additional information about the decomposition of R\&D expenditures of selected countries can be found in Table 1. Data in Table 1 indicate that in 2013, OECD countries as a group spent more than $\$ 1145$ billion for R\&D. This amount constitutes $2.40 \%$ of that year's aggregate OECD income. The leading countries in terms of R\&D expenditures are Israel $(4.21 \%)$ and Korea $(4.15 \%)$. They are followed by Japan $(3.48 \%)$, Sweden (3.30\%), and Finland (3.32\%) and Denmark (3.06\%). Lowest shares for R\&D can be observed around Southern Europe: Turkey, Greece, and Portugal. We can also observe that Mexico and the transition countries of Europe, especially Poland, Romania, and Slovakia also have lower R\&D shares compared to their respective national income.

Education expenditures display significant disparities across countries. For instance, it can be observed from Table 3 that OECD countries devote US\$9313 per student from primary to tertiary education. Data at this level are not available for Turkey, but for purposes of comparison, Turkey's average spending per student at the secondary education level is $\$ 2470$, and for primary education, it is $\$ 1860$. This magnitude is significantly below the OECD country averages of $\$ 9014$ and \$7974, respectively. Turkey is the last among our sample countries with the lowest expenditure on education per person, given available data (Table 3). According to the Ministry of National Education data, in Turkey, government expenditures on students in higher education reach four times of the government expenditures on students in basic education. Government expenditures on all levels of education are below OECD and EU countries; consequently, correction of the imbalances between higher education and other education levels is essential. 
Table 1. Components of R\&D expenditures in selected countries (2013 otherwise noted).

Gross domestic

expenditure on

R\&D - GERD

(current PPP,

Government-

Percentage of

GERD

GERD as a

financed GERD

Percentage of

million \$)

GDP

GDP

industry GERD

financed by

BERD as a

HERD as a

abroad

GDP

GDP

Country

Australia (2011)

$20,955.603$

$11,030.138$

$10,603.422$

2.128

Austria (2014)

Belgium

Canada

Chile (2012)

Czech Republic

Denmark

Estonia

Finland

France

Germany

Greece

Hungary

Iceland (2011)

Ireland (2012)

Israel

Italy

Japan

Korea

Luxembourg

Mexico (2011)

Netherlands

New Zealand (2011)

Norway

$24,565.359$

2.829

2.281

1.624

0.363

5812.939

1.905

7513.404

3.056

592.012

7175.595

1.739

3.320

$55,218.246$

2.231

$1,03,909.020$

2.936

2213.444

0.782

3249.569

1.408

2.495

314.837

1.576

3271.467

4.213

(1, 032.85

1.248

$26,520.410$

3.489

$68,936.980$

571.469

4.152

1.155

8058.471

0.426

$15,376.722$

1.982

1766.589

1.266

5538.577

1.094
0.504
0.566
0.131
0.662
0.894
0.835
0.864
0.778
0.840
0.403
0.505
0.998
0.430
0.515
0.536
0.604
0.960
0.431
0.254
0.680
0.524
0.758

44.486
60.151
46.449
34.946
37.595
59.780
41.283
60.838
55.378
66.074
32.061
46.802
49.845
35.599
44.288
76.115
75.479
75.680
20.463
36.755
47.101
39.962
44.197

16.382

12.961

5.955

17.536

27.152

7.177

10.348

11.542

7.616

4.323

13.317

16.569

8.218

21.356

48.774

9.455

0.524

0.304

20.408

0.692

14.274

6.324

7.786

1.231
1.935
1.576
0.820
0.125
1.031
2.000
0.830
2.286
1.445
1.992
0.272
0.977
1.326
1.136
3.486
0.674
2.655
3.260
0.709
0.166
1.140
0.575
0.870

0.632

0.720

0.494

0.646

0.124

0.519

0.971

0.736

0.714

0.463

0.514

0.293

0.203

0.658

0.364

0.593

0.352

0.470

0.384

0.177

0.123

0.630

0.403

0.526 


\begin{tabular}{|c|c|c|c|c|c|c|c|c|}
\hline \multicolumn{2}{|l|}{ Poland } & 7918.125 & 0.868 & 0.410 & 37.329 & 13.118 & 0.379 & 0.254 \\
\hline \multicolumn{2}{|l|}{ Portugal } & 3942.651 & 1.356 & 0.590 & 40.195 & 5.174 & 0.645 & 0.513 \\
\hline \multicolumn{2}{|c|}{ Slovak Republic } & 1190.628 & 0.830 & 0.323 & 40.195 & 17.966 & 0.384 & 0.275 \\
\hline \multicolumn{2}{|c|}{ Slovenia } & 1537.842 & 2.587 & 0.695 & 63.848 & 8.912 & 1.980 & 0.270 \\
\hline \multicolumn{2}{|l|}{ Spain } & $19,192.662$ & 1.244 & 0.547 & 45.643 & 6.647 & 0.662 & 0.348 \\
\hline \multicolumn{2}{|l|}{ Sweden } & $14,151.281$ & 3.302 & 0.931 & 60.954 & 6.800 & 2.276 & 0.896 \\
\hline \multicolumn{2}{|c|}{ Switzerland (2012) } & $13,251.399$ & 2.964 & 0.753 & 60.778 & 12.075 & 2.053 & 0.834 \\
\hline \multicolumn{2}{|c|}{ Turkey } & $13,315.103$ & 0.946 & 0.251 & 48.875 & 0.830 & 0.449 & 0.398 \\
\hline \multicolumn{2}{|l|}{$\mathrm{UK}$} & $39,858.827$ & 1.625 & 0.439 & 46.547 & 20.646 & 1.048 & 0.427 \\
\hline \multicolumn{2}{|c|}{ USA (2012) } & $4,53,544.000$ & 2.806 & 0.864 & 59.129 & 3.799 & 1.959 & 0.388 \\
\hline \multicolumn{2}{|c|}{ EU (28 countries) } & $3,44,814.338$ & 1.925 & 0.642 & 54.275 & 9.785 & 1.213 & 0.448 \\
\hline & $11,45,045.262$ & 2.398 & 0.701 & 60.049 & 5.409 & 1.639 & 0.425 \\
\hline \multirow{6}{*}{$\begin{array}{l}\text { OECD - tota } \\
\text { Non-OECD } \\
\text { member } \\
\text { economies }\end{array}$} & $\begin{array}{l}\text { Argentina } \\
(2012)\end{array}$ & 5185.838 & 0.584 & 0.432 & 21.340 & 0.582 & 0.125 & 0.182 \\
\hline & China & $3,36,495.439$ & 2.019 & 0.426 & 74.601 & 0.894 & 1.547 & 0.146 \\
\hline & Romania & 1452.925 & 0.386 & 0.202 & 31.018 & 15.504 & 0.118 & 0.076 \\
\hline & Russia & $40,694.501$ & 1.123 & 0.760 & 28.159 & 3.034 & 0.681 & 0.101 \\
\hline & $\begin{array}{l}\text { Singapore } \\
(2012)\end{array}$ & 8149.318 & 2.021 & 0.779 & 53.373 & 5.908 & 1.231 & 0.587 \\
\hline & $\begin{array}{l}\text { South } \\
\text { Africa } \\
(2012)\end{array}$ & 4870.706 & 0.760 & 0.345 & 38.339 & 13.057 & 0.337 & 0.234 \\
\hline
\end{tabular}

Source: OECD, Istat (2013b). 
Table 2. R\&D personnel in selected countries (2013 otherwise noted).

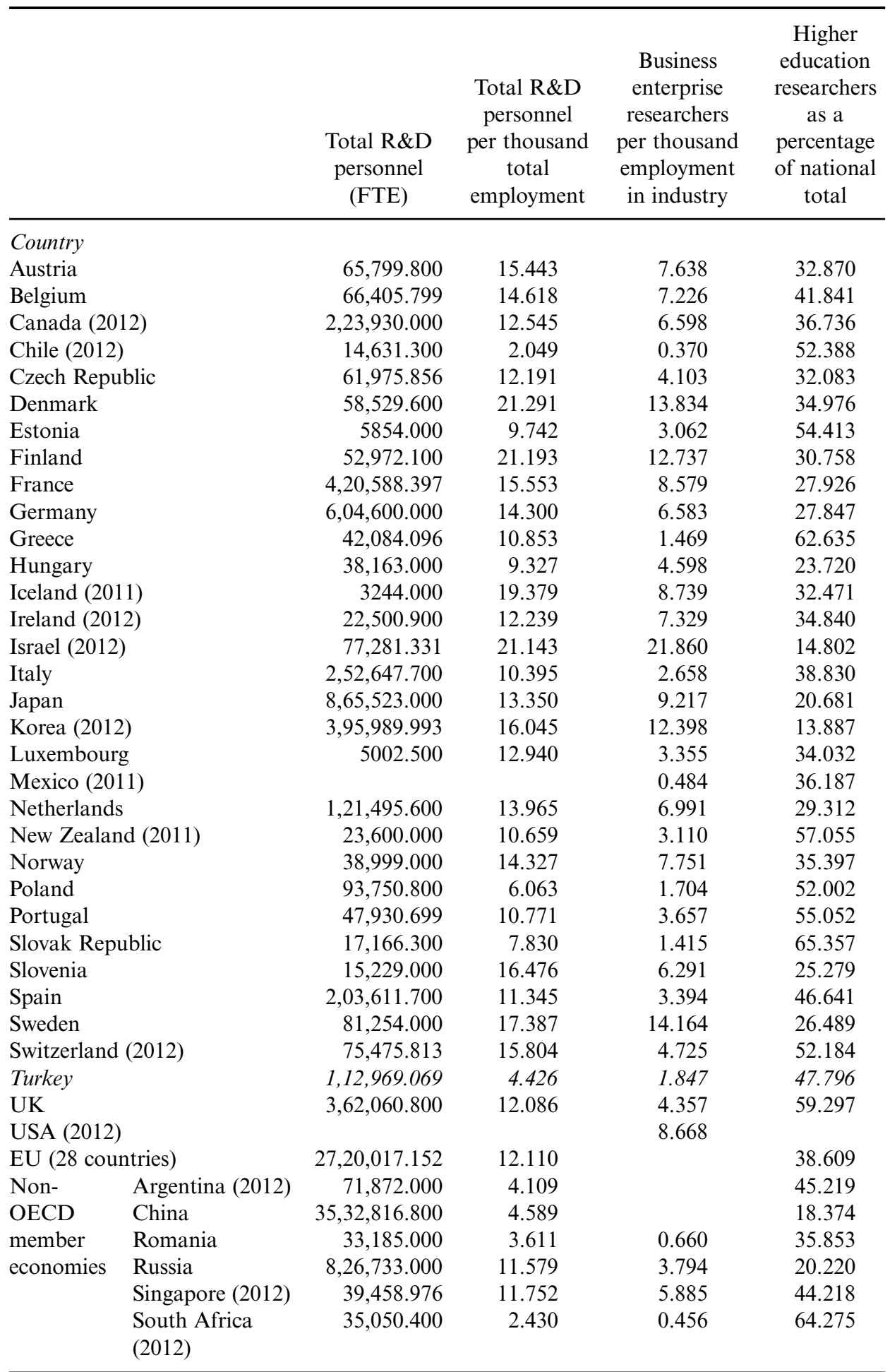

Source: OECD, Istat (2013b). 
Table 3. Annual expenditure per student by educational institutions, 2010 (PPP US\$, for fulltime equivalents).

\begin{tabular}{|c|c|c|c|c|c|}
\hline & $\begin{array}{l}\text { Pre- } \\
\text { primary } \\
\text { education }\end{array}$ & $\begin{array}{l}\text { Primary } \\
\text { education }\end{array}$ & $\begin{array}{l}\text { Secondary } \\
\text { education }\end{array}$ & $\begin{array}{c}\text { Tertiary } \\
\text { education }\end{array}$ & $\begin{array}{c}\text { Primary to tertiary } \\
\text { education } \\
\text { (including R\&D) }\end{array}$ \\
\hline \multicolumn{6}{|l|}{ Country } \\
\hline Argentina $^{\mathrm{a}}$ & 2427 & 2929 & 3930 & 4680 & 3628 \\
\hline Australia & 8899 & 9463 & 10,350 & 15,142 & 10,825 \\
\hline Austria & 8893 & 10,244 & 12,551 & 15,007 & 12,507 \\
\hline Belgium & 6024 & 8852 & 11,004 & 15,179 & 11,028 \\
\hline Brazil $^{\mathrm{a}}$ & 2111 & 2778 & 2571 & 13,137 & 3067 \\
\hline Canada $^{\mathrm{ab}}$ & & 8933 & 11,317 & 22,475 & \\
\hline Chile (2011) & 3544 & 3301 & 3119 & 7101 & 4183 \\
\hline Czech Republic & 4247 & 4120 & 6546 & 7635 & 6037 \\
\hline Denmark & 9454 & 10,935 & 11,747 & 18,977 & 12,848 \\
\hline Estonia & 2533 & 5140 & 6444 & 6501 & 6126 \\
\hline Finland & 5372 & 7624 & 9162 & 16,174 & 10,157 \\
\hline France & 6362 & 6622 & 10,877 & 15,067 & 10,182 \\
\hline Hungary $^{\mathrm{a}}$ & 4773 & 4684 & 4553 & 8745 & 5285 \\
\hline Iceland & 8606 & 9482 & 7841 & 8728 & 8619 \\
\hline Ireland $^{\mathrm{a}}$ & & 8384 & 11,380 & 16,008 & 10,685 \\
\hline Israel & 3910 & 5758 & 5616 & 10,730 & 6537 \\
\hline Italy $^{\mathrm{a}}$ & 7177 & 8296 & 8607 & 9580 & 8680 \\
\hline Japan & 5550 & 8353 & 9957 & 16,015 & 10,596 \\
\hline Korea & 6739 & 6601 & 8060 & 9972 & 8198 \\
\hline Luxembourg & 20,958 & 21,240 & 17,633 & & \\
\hline Mexico & 2280 & 2331 & 2632 & 7872 & 2993 \\
\hline Netherlands & 7664 & 7954 & 11,838 & 17,161 & 11,439 \\
\hline New Zealand & 11,495 & 6842 & 8170 & 10,418 & 8192 \\
\hline Norway & 6610 & 12,525 & 13,852 & 18,512 & 14,081 \\
\hline Poland $^{\mathrm{a}}$ & 5737 & 5937 & 5483 & 8866 & 6321 \\
\hline Portugal $^{\mathrm{a}}$ & 5977 & 5922 & 8882 & 10,578 & 8009 \\
\hline Slovak Republic & 4306 & 5732 & 4806 & 6904 & 5400 \\
\hline Slovenia & 7744 & 8935 & 8187 & 9693 & 8933 \\
\hline Spain & 6685 & 7291 & 9608 & 13,373 & 9484 \\
\hline Sweden & 6582 & 9987 & 10,185 & 19,562 & 11,734 \\
\hline Switzerland $^{\mathrm{a}}$ & 5186 & 11,513 & 14,972 & 21,893 & 14,922 \\
\hline Turkey & 2490 & 1860 & 2470 & & \\
\hline UK & 7047 & 9369 & 10,452 & 15,862 & 10,878 \\
\hline USA & 10,020 & 11,193 & 12,464 & 25,576 & 15,171 \\
\hline OECD average & 6762 & 7974 & 9014 & 13,528 & 9313 \\
\hline EU-21 average & 7085 & 8277 & 9471 & 12,856 & 9208 \\
\hline
\end{tabular}

${ }^{\text {a }}$ Public institutions only.

${ }^{\mathrm{b}}$ Data refer to 2009 .

Source: OECD (2013a).

Moreover, if concentration of population in this age group is taken into account, it can be better understood that government expenditures on these levels are insufficient in reference to international standards. 
As a follow-up of these observations, there exist considerable concerns about the general outlook and quality of Turkish education performance. For instance, in its 2011 Annual Program document, the SPO (Ministry of Development) drew attention to the most important structural defects in the Turkish education system with the assessment that access to education and education quality are the most fundamental problems of the education system (SPO, 2011, p. 198). According to the same document,

schooling ratio and disparities between regions and genders are among the most acute areas within the scope of accessibility, where inadequacy of physical infrastructure, updating of curriculum, development of teacher qualifications and harmonization of the curriculum and education costs are the main concerns as far as the quality of education services is concerned. (SPO, 2011, p. 198)

A recent TÜSIADD project report further asserts that Turkey ranks 97th in the ratio of literates to the population 15 years and older (TÜSİAD, 2011). In the age bracket 25-34, the share of high school diplomas reaches only $41 \%$, and that of university degree holders to $16.6 \%$. Under both categories, Turkey ranks 33rd among 34 OECD countries.

Hence, according to these assessments, despite the positive developments of the schooling ratios at early levels of education, higher degrees that are not protected under legal compulsory education coverage fall short of the mark in comparison to OECD and EU averages. Table 4 presents these data. Finally, we report on the state of the young in education. OECD (2013a) defines those people who are not in the labor force, nor in education as inactive labor. According to OECD data, among the young (ages 15-29), the ratio of inactive labor in total population reaches $38 \%$ in Turkey, while the OECD average is $24 \%$ (Figure 1). In contrast, the share of young people engaged in education activities is $32 \%$ in Turkey in contrast to the OECD average of $47 \%$. Turkey fares significantly worse in this indicator.

All these suggest that Turkey is severely under-investing in R\&D and in education. The issue, then, is how to prioritize scarce resources - especially public funds - to invigorate $R \& D$ and human capital-driven growth? We first introduce the salient features and algebraic characteristics of our model that will be implemented to tackle the analytics of this question.

\section{The model structure}

The model is a direct application of the recent advances in the literature of the new growth theory, and is built on the complementarities between R\&D-driven technological change and human capital acquisition. The algebraic structure of the model is

Table 4. Schooling ratio according to age brackets.

\begin{tabular}{lcccc}
\hline & Ages 3-4 & Ages 5-14 & Ages 15-19 & Ages 20-29 \\
\hline Turkey & 7.9 & 91.9 & 45.9 & 12.9 \\
OECD average & 71.5 & 98.9 & 81.5 & 24.9 \\
EU-19 average & 79.8 & 99 & 84.9 & 25.1 \\
\hline
\end{tabular}

Source: OECD (2013a). 


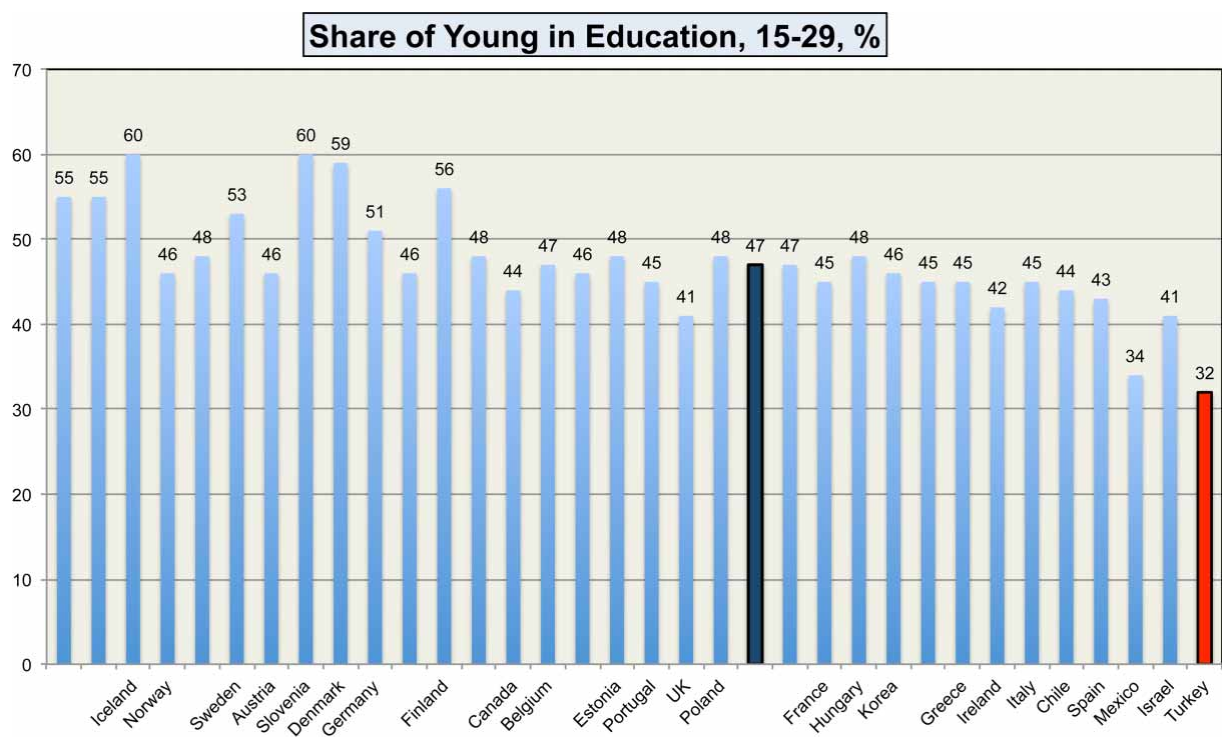

Figure 1. Share of young in education, 15-29, \%.

presented in five subsections, starting with the final output production, concluding with the conditions for equilibrium and discussion of the macroeconomic identities.

\subsection{Production activities}

The economy is presumed to be open, and is small in the world markets. It accommodates four activities in the aggregate, three of which are production activities: (i) production of a final good, $Y$; (ii) production of capital input varieties, $k(i)$ to be used as inputs in the production of $Y$; and (iii) production of R\&D (blueprints, ideas, etc.). A final activity further entails education services (human capital formation).

Final output is produced using plain labor, $L^{Y}$, human capital (skilled labor), $H^{Y}$, and differentiated capital varieties as inputs:

$$
Y_{t}=A_{Y} L_{t}^{Y \alpha_{L}} H_{t}^{Y \alpha_{H}} \int_{i=0}^{A_{t}} k_{t}(i)^{\alpha_{k}} \mathrm{~d} i
$$

with $\alpha_{L}+\alpha_{H}+\alpha_{k}=1.0$. All differentiated capital varieties are of equal quantity and are valued equally. They are produced by symmetric firms (each capital variety is produced by a single oligopolist firm). That is, $k(i)=k$ for all $i \in\left[1, A_{t}\right]$. Therefore, we have at any moment, $\int_{0}^{A} k_{t}(i)^{\alpha_{k}}=A_{t} k_{t}^{\alpha_{k}}$.

Note that the $Y$-sector uses $L^{Y}, H^{Y}$, and a series of inputs $\left\{k_{1} \ldots k_{A}\right\}$; where $\{A\}$ is the index of varieties of capital inputs available to this economy. As new research leading to new innovations is conducted, the index set $\{A\}$ expands. Following the idea in Funke and Strulik (2000) and based on applications of Sequeira (2010, 2011) and Voyvoda and Yeldan (2011), this is achieved in the R\&D sector as follows:

$$
A_{t+1}-A_{t}=\varphi H_{t}^{A}
$$


New research is generated solely by human capital allocated to the production of new ideas (research personnel), $H_{A}$ and excludes decreasing returns as well as the scale effects of $A .{ }^{1}$ The research productivity of each researcher is a factor $\varphi>0$. In what follows, an additional driving source of this economy is the rate of human capital formulation:

$$
H_{t+1}-H_{t}=\xi H_{t}^{H}+\gamma H_{t}^{\epsilon} A_{t}^{1-\epsilon}
$$

In Equation (3), human capital is a non-market activity and is thought to be 'produced' via human capital allocated to education, $H_{H}$, and the existing stock of ideas $A$. Past accumulation of human capital is also necessary to generate further human capital (students cannot be trained without teachers). Generation of $H$ is the endresult of schooling $\left(\xi H^{H}\right)$, where the parameter $\xi$ acts as the productivity of schooling and sets the incentive to spend time in education. Sequeira (2011) refers to the second term on the right-hand side as 'learning with varieties' since it is a composite of the stock of human capital and the existing knowledge (ideas) in the economy. This effect is driven by a productivity parameter, $\gamma$, which measures the relative importance of 'learning with existing knowledge'. The elasticity parameter $\epsilon$ measures the intensity of human capital to capture the existing knowledge.

As human capital expands, research workers keep on producing new ideas at a constant speed. The growth rate of knowledge production, $g^{A}$, becomes

$$
g_{t}^{A}=\frac{A_{t+1}-A_{t}}{A_{t}}=\varphi \frac{H_{t}^{A}}{A_{t}}
$$

and remains constant under steady state when the share of human capital allocated to research, $u_{t}^{A}=\left(H_{t}^{A} / H_{t}\right)$, stabilizes. So, defining $H_{t+1} / H_{t}=\left(1+g_{t}^{H}\right)$, the growth rate of human capital becomes

$$
g_{t}^{H}=\xi \frac{H_{t}^{H}}{H_{t}}+\gamma\left(\frac{A_{t}}{H_{t}}\right)^{1-\epsilon} .
$$

At the balanced growth path, $g_{t}^{H}$ is constant as long as the ratio of total available number of ideas to the stock of human capital remain stable. These formulations further necessitate that a steady-state solution with a constant rate of growth requires a constant allocation of $H_{t}$ along its components. This means that, under long-run equilibrium, infinitely lived people will dedicate in each period a constant share of time between working and schooling.

In contrast to the monopolistically competitive structure of the intermediate capital variety markets, the final good sector works under perfectly competitive conditions. The producer hires both types of labor and the capital varieties up to the point where the value of the marginal product of each factor is equated to its wage and rental costs, respectively. Therefore, labor is demanded according to

$$
w_{t}^{L}=P_{t}^{Y} \frac{\partial Y_{t}}{\partial L_{t}^{Y}} .
$$


Human capital demand is similar

$$
w_{t}^{H}=P_{t}^{Y} \frac{\partial Y_{t}}{\partial H_{t}^{Y}} .
$$

Capital varieties are demanded along the functions,

$$
p_{t}^{k}(i)=P_{t}^{Y} \alpha_{k} L_{t}^{Y \alpha_{L}} H_{t}^{Y \alpha_{H}} k_{t}(i)^{\alpha_{k}-1}, \quad i=1, \ldots, A_{t}
$$

In the $R \& D$ sector, given public subsidies on $R \& D$ costs, human capital is demanded so as to satisfy its marginal productivity condition:

$$
w_{t}^{H}=\frac{P_{t}^{A} \varphi}{\left(1-s^{R}\right)} .
$$

Here, $s^{R}$ represents the subsidy rate to accumulate human capital in the R\&D sector. Note that competitive conditions in factor markets necessitate that wage costs of human capital are equated across its uses in the R\&D sector and in the final goods production sector. Thus, $w_{t}^{H}=\left(P_{t}^{A} /\left(1-s^{R}\right)\right) \varphi=P_{t}^{Y} \alpha_{H}\left(Y_{t} / H_{t}^{Y}\right)$.

\subsection{The differentiated capital and investment decision}

'Capital' is modeled here as a heterogenous input which accumulates by the varieties, $k(i)$. The intermediate firm purchases blueprints (the technological knowledge generated in the R\&D sector) and according to the instructions therein, produces a new capital variety. The number of new capital varieties produced at period $t$ is equal to the number of new blueprints produced in the same period, $A_{t}$. Thus, ignoring depreciation, the number of accumulated capital varieties in the economy at time period $t$ is equal to the number of blueprints available in the economy. Each new capital input $k(i)$ is produced by using real resources and other inputs at a constant ratio, $\eta$, where $\eta$ acts as the input-output coefficient to produce one unit of $k(i)$. Cost of $\eta$, at the margin is $r$, the interest rate in the economy.

Now, observe that as the intermediate producer has purchased the R\&D blueprints, she has incurred the upfront fixed costs of research. These research costs totaling, $P_{t}^{A}$, have to be borne up-front by the intermediate capital variety firm. Thus, the expression $P_{t}^{A} \Delta A_{t}$ becomes the fixed costs of production of $k_{t}(i)$, and leads to increasing returns in its production. Since the $i$ th firm has monopoly rights in the production of $k_{t}(i)$, it acts as a monopolistically competitor in the capital varieties markets. Taking the demand function for $k_{t}(i)$ from the final good producer's optimization problem (8) as given, each monopolistically competitive firm seeks to maximize the monopolistic profits,

$$
\max _{k_{t}(i)} \pi_{t}(i)=p_{t}^{k}(i) \cdot k_{t}(i)-\eta r_{t} k_{t}(i)-P_{t}^{A} \Delta A_{t}
$$

In Equation (10), the term $\eta r_{t} k_{t}(i)$ is the variable costs of production. For each unit of $k_{i}$ produced, $\eta$ units of other inputs are rented out at the interest rate $r_{t}$. The solution of Equation (10) reveals that the profit maximizing price $p_{t}^{k}(i)$ is given by a mark-up 
over the marginal costs, $\eta r_{t}$. Using the demand for $k_{t}(i)$ from the final good producer's decision, we have the following optimal pricing rule for the monopolistically competitive firm:

$$
P_{t}^{Y} \alpha_{k}^{2} L_{t}^{Y \alpha_{L}} H_{t}^{Y \alpha_{H}} k_{t}(i)^{\alpha_{k}-1}=\eta r_{t} .
$$

Therefore, the optimal quantity of the capital variety is set via

$$
k_{t}(i)=\left[\frac{P_{t}^{Y} \alpha_{k}^{2} L_{t}^{Y \alpha_{L}} H_{t}^{Y \alpha_{H}}}{\eta r_{t}}\right]^{1 /\left(1-\alpha_{k}\right)}
$$

The size of the monopolistic mark-up is $1 / \alpha_{k}$.

$$
p_{t}^{k}(i)=\frac{P_{t}^{Y} \eta r_{t}}{\alpha_{k}}
$$

Since all firms are symmetric and they all set the same price in Equation (12) to sell their respective capital varieties, we will take $p_{t}^{k}(i)=p_{t}^{k}$ and $k_{t}(i)=k_{t} \forall i$. Under these conditions, the maximal profits are given by

$$
\pi_{t}^{\max }\left(k_{t}\right)=p_{t}^{k} \cdot k_{t}-\eta r_{t} \cdot k_{t}=\left(p_{k}-\eta r_{t}\right) k_{t}
$$

Since $r_{t}=\left(\alpha_{k} p_{t}^{k} / \eta\right)$ from above, we can express maximal profits of the monopolistically competitive firms as

$$
\pi_{t}^{\max }\left(k_{t}\right)=\left(1-\alpha_{k}\right) p_{t}^{k} k_{t}
$$

The monopolistically competitive firms have a forward-looking behavior. That is, they make investment decisions on developing new blueprints and producing new capital varieties so as to maximize the long-run expected returns from an infinite stream of monopolistic profits. In particular, the expected returns from investment must be comparable with those from holding a 'safe' asset such as bonds or bank deposits. Thus, asset market equilibrium requires, for any point in time, that the following no-arbitrage condition holds:

$$
\pi_{t}+\left(P_{t}^{A}-P_{t-1}^{A}\right)=r_{t} P_{t-1}^{A}
$$

where the term $\left(P_{t}^{A}-P_{t-1}^{A}\right)$ denotes changes in the valorization of the $i$ th firm over time. In equilibrium, the value of the firm is equal to aggregate investment expenditures of this firm, which includes the cost of developing a new blueprint $\left(P_{t}^{A}\right)$, plus the material costs of investment goods. Imposition of the transversality condition to rule out speculative bubbles gives

$$
P_{t}^{A}=\sum_{t=0}^{\infty} R(t) \pi_{t},
$$


that is, the value of the monopolistically competitive firm is equal to the discounted value of the stream of monopolistic profits, where $R(t)$ is a discount factor defined according to

$$
R(t)=\prod_{s=0}^{t}(1+r)^{-1} .
$$

Note that, the above no-arbitrage condition can also be expressed more succinctly as

$$
\left(1+r_{t}\right) P_{t-1}^{A}=\pi_{t}+P_{t}^{A} .
$$

Investment expenditures in this model are used in generating new research and producing new capital varieties:

$$
I_{t}^{D}=\eta\left[\left(A_{t+1}-A_{t}\right) k_{t}+\left(k_{t+1}-k_{t}\right) A_{t}\right]
$$

\subsection{Consumption and savings decisions}

Households are endowed with human capital, $H_{t}$ in each period, and allocate it among three uses, final good production, knowledge production and further human capital formation:

$$
H_{t}=H_{t}^{Y}+H_{t}^{H}+H_{t}^{A}
$$

where $\left(H_{t}-H_{t}^{H}\right)$ is associated with a wage rate $w_{t}^{H}$ and $H_{t}^{H}$ is subsidized through $s^{H} w_{t}^{H}$. The representative household maximizes a utility function of the form:

$$
\max U_{0}=\sum_{t=0}^{\infty} \beta^{t} \frac{c_{t}^{1-\theta}-1}{1-\theta}
$$

subject to

$$
\begin{aligned}
& \sum_{t=0}^{\infty} R(t) P_{t}^{C} c_{t}=\mathrm{TW}_{0} \\
& H_{t+1}-H_{t}=\xi H_{t}^{H}+\gamma H_{t}^{\epsilon} A_{t}^{1-\epsilon}
\end{aligned}
$$

with control variables $c_{t}>0$ and $H_{t}^{H} \geq 0$. Here, $\mathrm{TW}_{0}$ is total wealth, which includes the present value of period-wise income. $Y_{t}^{H}=\left(1-t^{Y}\right)\left[w_{t}^{H}\left(H_{t}-H_{t}^{H}\right)+s^{H} w_{t}^{H} H_{t}^{H}+w_{t}^{L} L_{t}^{Y}+p_{t}^{k} k_{t} A_{t}\right]$ is the private household disposable income composed of returns to primary factors of production and the value of capital variety producing firms. 
The first-order conditions (F.O.C) associated with the maximization problem above are twofold:

$$
\begin{gathered}
\beta\left(1+r_{t+1}\right)\left(\frac{c_{t+1}}{c_{t}}\right)^{\theta}=\frac{P_{t+1}^{C}}{P_{t}^{C}}, \\
\frac{w_{t}^{H}}{w_{t+1}^{H}}=\frac{1}{1+r_{t+1}}\left(\frac{\xi}{\left(1-s^{H}\right)}+1 \gamma \epsilon\left(\frac{H_{t+1}}{A_{t+1}}\right)^{1-\epsilon}\right) \text { with } H^{H}>0 .
\end{gathered}
$$

Here, the first condition is the discrete version of the standard Ramsey rule. The second equation implies that the growth rate of wages must be sufficiently high compared to the interest rate to ensure positive investment in human capital.

Using $\left(1-s^{R}\right) w_{t}^{H} / \varphi=P_{t}^{A}$ from Equation (9), we get

$$
\frac{w_{t+1}^{H}}{w_{t}^{H}}=\frac{P_{t+1}^{A}}{P_{t}^{A}} .
$$

Here, the rate of growth of $P_{t}^{A}$ is narrated in the no-arbitrage condition as spelled in Equation (15). Inserting in these equations for $\pi_{t}$ and $P_{t}^{A}$ and equating the two expressions for $w_{t+1}^{H} / w_{t}^{H}$ give us

$$
1+\frac{1-\alpha_{k}}{\alpha_{H}} \varphi \alpha_{k} \frac{u_{t+1}^{Y} H_{t+1}}{A_{t+1}}=\frac{\xi}{\left(1-s^{H}\right)}+\left(1+\gamma \epsilon\left(\frac{H_{t+1}}{A_{t+1}}\right)^{(1-\epsilon)}\right) .
$$

Now assume that we denote the share of $H_{t}$ allocated to final goods production, $H_{t}^{Y}$ as $u_{t}^{Y}$. The equation above should provide the value of $u_{t+1}^{Y}$, given $H_{t+1} / A_{t+1}$ which is critical in terms of the allocation of human capital to different sectors of the economy. It also implies $u_{t+1}^{Y}=u^{Y}$ at the steady state.

\subsection{National income identities and equilibrium growth}

Intra-temporal equilibrium requires that at each time period, (1) demand for primary factors $\left(L^{Y}, H^{A}, H^{Y}\right)$ equals their respective supplies; (2) human capital allocation among the final food production, $Y, \mathrm{R} \& \mathrm{D}$ production, $\Delta A$, and education, $\Delta H$ activities exhausts its total supply; (3) domestic demand and export demand for the output of each sector equal its supply; (4) the output of R\&D, that is the number of new blueprints, equals the number of new capital varieties invested; (5) household savings equal investment-costs of new blueprints plus costs of investment goods in capital variety production; and (6) the government budget is satisfied. These conditions imply that the commodity market is in equilibrium with

$$
C C_{t}=C_{t}+G_{t}+I_{t}^{D}
$$


Saving investment balance is maintained through

$$
S_{t}=P_{t}^{C} I_{t}^{D}+P_{t}^{A} \Delta A_{t}
$$

The government's budget is in balance:

$$
P_{t}^{C} G_{t}+s^{H} w_{t}^{H} H_{t}^{H}+s^{R} w_{t}^{H} H_{t}^{A}=\mathrm{GREV}_{t}
$$

with government revenues equal to total tax revenues. ${ }^{2}$

Gross domestic product (GDP) at factor cost (exclusive of production taxes) is the sum of value added of the final good, human capital expenditures, and the R\&D sectors:

$$
\begin{gathered}
\mathrm{GDP}_{t}=P_{t}^{Y} Y_{t}+P_{t}^{A} \Delta A_{t}, \\
=w_{t}^{L} L_{t}^{Y}+w_{t}^{H}\left(H_{t}^{Y}+H_{t}^{A}\right)+\sum_{i=1}^{A_{t}} p_{t}^{k}(i) k_{t}(i) .
\end{gathered}
$$

Using $\sum_{i=1}^{A_{t}} p_{t}^{k}(i) k_{t}(i)=p_{t}^{k} A_{t} k_{t}$, which in turn will be equal to $\alpha_{k} P_{t}^{Y} Y_{t}$, the identity in Equation (25) can also be written as

$$
p_{t}^{k} A_{t} k_{t}=\alpha_{k}\left(\mathrm{GDP}_{t}-P_{t}^{A} \Delta A_{t}\right)
$$

or, using Equation (25),

$$
\begin{aligned}
{\left[\mathrm{GDP}_{t}-w_{t}^{L} L_{t}^{Y}-w_{t}^{H}\left(H_{t}^{Y}+H_{t}^{A}\right)\right] } & =p_{t}^{k} A_{t} k_{t} \\
& =\alpha_{k} P_{t}^{Y} Y_{t}
\end{aligned}
$$

Furthermore, using the definition of profits from Equation (14), the GDP identity can also be written as

$$
P_{t}^{Y} Y_{t}+P_{t}^{A} \Delta A_{t}=w_{t}^{L} L_{t}^{Y}+w_{t}^{H}\left(H_{t}^{Y}+H_{t}^{A}\right)+A_{t} \frac{\pi}{\left(1-\alpha_{k}\right)} .
$$

In the steady-state equilibrium, all quantity variables grow at a constant rate which is proportional to the growth rate of human capital formation. All prices, including prices for final goods produced and consumed domestically, the unit cost of the R\&D output, differential capital varieties, and the interest rate grow at a constant rate in the steady state. Also, the allocation of $H_{t}$ among its uses will be constant; hence, given $H_{t}^{Y}=u^{Y} H_{t}, H_{t}^{A}=u^{A} H_{t}$ and $H_{t}^{H}=u^{H} H_{t}$, with $u^{A}+u^{H}+u^{Y}=1$.

Based on these specifications, and the growth rates of $H, g_{t}^{H}$ and $A, g_{t}^{A}$ implies that at steady state $H_{t} / A_{t}$ is constant. Combining the definitions of $g_{t}^{H}$ and $g_{t}^{A}$, we have $g^{H}=g^{A}$ at the steady state. 
We know that $w_{t}^{H}$ in the $\mathrm{R} \& \mathrm{D}$ sector is the same as the $w_{t}^{H}$ in the final goods sector. Equating the two, we have

$$
\begin{aligned}
\frac{P_{t}^{A} \varphi}{1-s^{R}} & =\alpha_{H} L_{t}^{Y \alpha_{L}} H_{t}^{Y \alpha_{H}-1} A_{t} k_{i}^{\alpha}, \\
P_{t}^{A} & =\frac{\alpha_{H} L_{t}^{Y \alpha_{L}} H_{t}^{Y^{\alpha_{H}-1}} A_{t} k_{i}^{\alpha}\left(1-s^{R}\right)}{\varphi} .
\end{aligned}
$$

Similarly,

$$
\pi_{t}(i)=\left(1-\alpha_{k}\right) \alpha_{k} L_{t}^{Y^{\alpha_{L}}} H_{t}^{Y^{\alpha_{H}}} k_{i}^{\alpha_{k}}
$$

Therefore,

$$
\left(1+g^{P^{A}}\right)=r_{t}-\frac{\left(1-\alpha_{k}\right)}{\alpha_{H}} \alpha_{k} \frac{H_{t}^{Y}}{A_{t}} \varphi .
$$

Since we now have the solution for $P_{t}^{A}$ here, we can also derive the growth rate $P_{t}^{A}$ at the steady state as

$$
\left(1+g^{P^{A}}\right)=\left(1+g^{H}\right)^{\alpha_{H} /\left(1-\alpha_{k}\right)} .
$$

Finally, since $Y_{t}=A_{Y} L_{t}^{Y^{\alpha_{L}}} H_{t}^{Y^{\alpha_{H}}} \sum_{i=0}^{A_{t}} k_{t}(i)^{\alpha_{k}}$, we have

$$
\frac{Y_{t+1}}{Y_{t}}=\left(\frac{L_{t+1}^{Y}}{L_{t}^{Y}}\right)^{\alpha_{L}}\left(\frac{H_{t+1}^{Y}}{H_{t}^{Y}}\right)^{\alpha_{H}} \frac{A_{t+1}}{A_{t}}\left(\frac{k_{t+1}}{k_{t}}\right)^{\alpha_{k}} .
$$

So, under the steady state

$$
\left(1+g^{Y}\right)=\left(1+g^{H}\right)^{\left(1+\alpha_{H}-\alpha_{k}\right) /\left(1-\alpha_{k}\right)} .
$$

\section{Policy analysis: dynamic effects of the selected public policies}

\subsection{Base-path equilibrium}

Now we will turn to the investigation of alternative public subsidization programs to promote growth and welfare within the context of our analytical model. In this exercise, our first step will be the construction of a business-as-usual base-path against which alternative policy scenarios are to be contrasted. To this end, we will follow the long-run growth trajectory of the Turkish economy under the historically realized parametric values starting from its 2005 equilibrium onwards.

As a starting reference point, the base-path assumes an annual rate of growth of $1.5 \%$ over a time span of 90 periods. Note that this rate narrates growth of only the TFP content of the growth of the GDP. To this value, addition of the growth in population and of other factors of production will yield the aggregate rate of growth of the national economy. It is further assumed that the ratio of $R \& D$ investment 


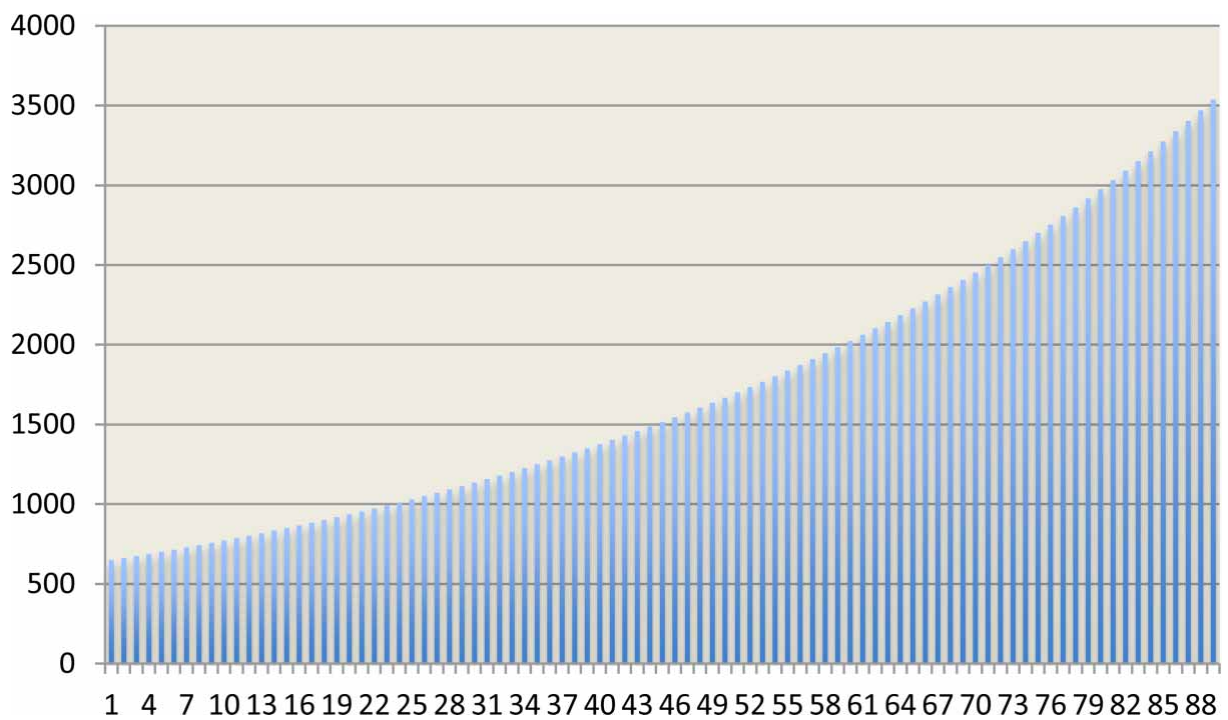

Figure 2. GDP under the base-path (Billions TL, Fixed 2005 Prices).

expenditures to GDP is $0.95 \%$. The equilibrium rate of interest is taken as $5 \%$. Under these specifications, the share of differentiated capital income in gross value added $\left(\alpha_{k}\right)$ is calculated to be 0.65 . The ratio of monopolistic profits to the national income, on the other hand, is calibrated to be $20 \%$.

Model simulations of the base-path under these specifications reveal that the value of GDP will reach to 3500 billions TL in fixed 2005 prices after 90 periods starting from the 2005 value of 648 billions TL. The path of the equilibrium level of GDP is portrayed in Figure 2.

Similarly, amounts of the stock of human capital and the index of R\&D can be envisaged over the time span of 90 periods under the base-path specification. Figures 3 and 4 display this information.

Values of the various other parameters and macroeconomic variables are displayed in Table A1 of the appendix. Now we turn to the analysis of alternative public subsidization regimes utilizing the base-path as a point of reference.

\subsection{Analysis of alternative subsidization programs}

In this subsection, we turn to the analysis of the basic mechanisms of growth-generating dynamics of the model, incorporating both accumulation of R\&D and accumulation of human capital. Since the framework employed here takes into account the complementarity between human capital and R\&D activities and the externalities associated with the accumulation of both, we first explore the basic mechanisms of 'correcting' the 'market failures' toward superior outcomes. To this end, we investigate two policy instruments, each of which promotes the accumulation of factors that are most needed in the production of the final good in the economy. Specifically, we first study subsidization of education expenditures (subsidy on the buildup of human capital through the skill-accumulation function via $s^{H}$ ) and contrast it with subsidization of the $R \& D$ activities (subsidy on the input costs to $\mathrm{R} \& \mathrm{D}$ via $s^{R}$ ). 


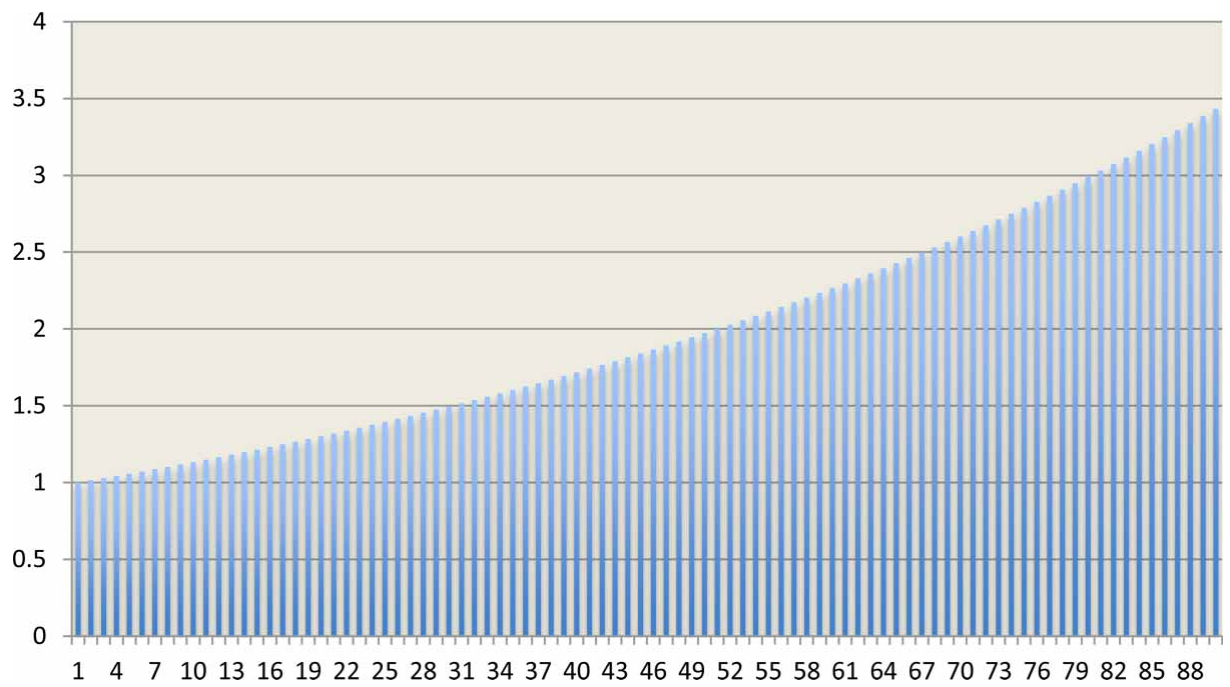

Figure 3. Evolution of the human capital stock under the base-path index values, period $1=1.00$.

The first policy experiment is designed to analyze the households' response to allocate human capital among different sectors and activities in the economy under the conditions of increased reward to education activities. Since the instrument, $s^{H}$, enters into the representative household's intertemporal maximization problem, we shall observe the effects on the derivation of future wages both in the final goods and the R\&D sectors of the economy and the trade-offs embedded between the two. The other policy instrument analyzed at this stage is designed to promote R\&D activities through a demand stimulus. It is implemented through the addition of an ad valorem subsidy to the input cost of the production of new R\&D. More

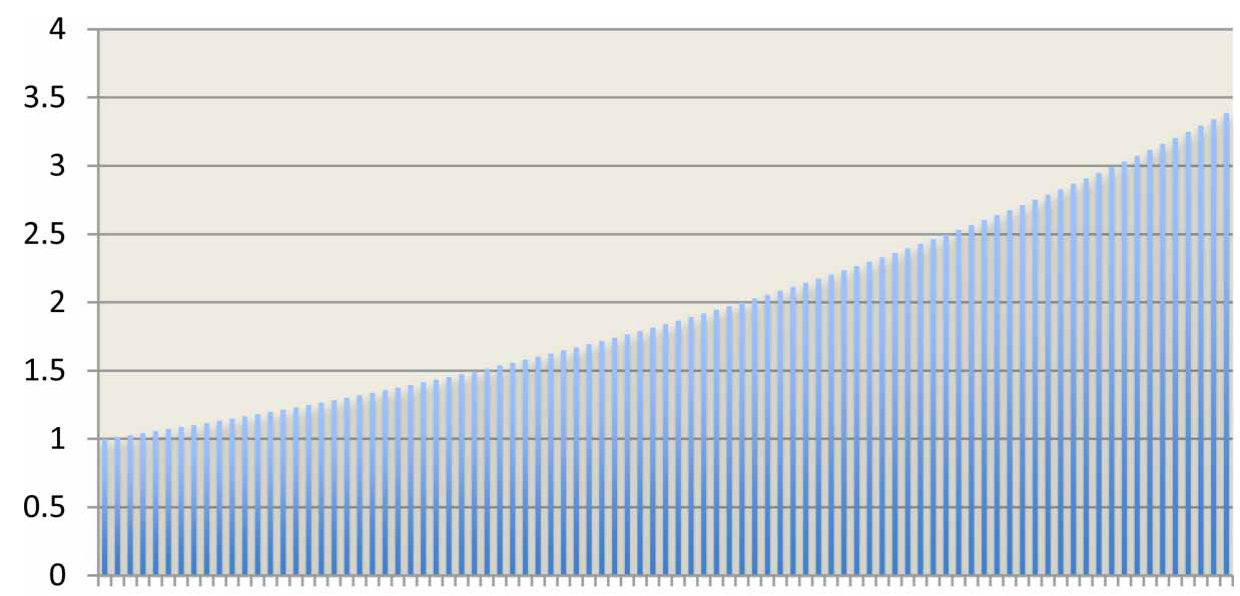

147101316192225283134374043464952555861646770737679828588

Figure 4. Aggregate R\&D stock under the base-path index values, period $1=1.00$. 
formally, our policy question can be stated succinctly as the following: for a government constrained by its budgetary requirements, which type of public subsidiziation policies are more conducive for enhancing growth and social welfare: promotion of human capital formation through subsidies to education expenditures, or promotion of new $R \& D$ formation through subsidies to $R \& D$ investment expenditures?

We will utilize the endogenous growth model, whose algebraic structure is presented above, to make a comparison between these two policy alternatives. First and foremost, we note that we ought to ensure that the budgetary costs of both policies remain equal (as a ratio to GDP) in order to compare alternative policy interventions quantitatively. For this reason, stimulation of the cost of fiscal intervention is designed to be $1 \%$ of national income, and the corresponding subsidy ratio is solved by the model endogenously. Solutions of the model indicate that an equivalent subsidy of $1 \%$ of national income corresponds to $4.0 \%$ for the human capital subsidy program, and $4.3 \%$ for the R\&D subsidy program. The fiscal authority, bounded by a public budget constraint, adjusts government consumption expenditures to set funds for subsidies. Hence, the subsidy system does not lay extra burden to the public budget.

Our results indicate that under both policy regimes, growth in output is above the long-run base-path. Since the growth rate depends on a variety of factors, the announced government subsidy creates complicated general equilibrium dynamics. Government subsidy to investment cost of each new blueprint (R\&D) stimulates the differentiated capital good production and raises the production of further R\&D activity. This, in turn, encourages resources to move away from other sectors and activities. Under the alternative policy scenario where we analyze the impact of dedication of human capital across different sectors by subsidizing education, we run into different trade-offs in human capital formation versus R\&D investments. One should note that government subsidy to human capital accumulation appears within the intertemporal optimization problem of private individuals. This decision involves recognition of the signals emanating from the wage rate differences from the production of the final good versus the R\&D activity.

It can be observed that the government subsidy on human capital devoted to education activities leads to the reallocation of resources away from the R\&D sector and channels them to human capital accumulation. This kind of a restructuring enables a higher level of human capital available to the economy, yet it results in lower R\&D activity in the immediate short run.

In the case of the subsidy to R\&D investment (through the $s_{R}$ parameter), production of $\mathrm{R} \& \mathrm{D}$ is elevated to a higher equilibrium level compared to the basepath. On the other hand, since both human capital devoted to R\&D and human capital employed for education are both effective for human capital production, we do not experience any significant reduction of human capital production as a whole. Figure 5 presents the disparate paths of the GDP under alternative policy regimes relative to the base-path.

Our results indicate that government's subsidization of the private education expenditures generates very strong growth effects initially, and yet, after this initial positive impact, the growth stimulating effects of the policy turn negative and weaken. Under this policy, initiation of the education subsidy leads to a higher level of human capital devoted to education activities. Remaining resources will be shared between R\&D and final good production sectors. Employment of more 


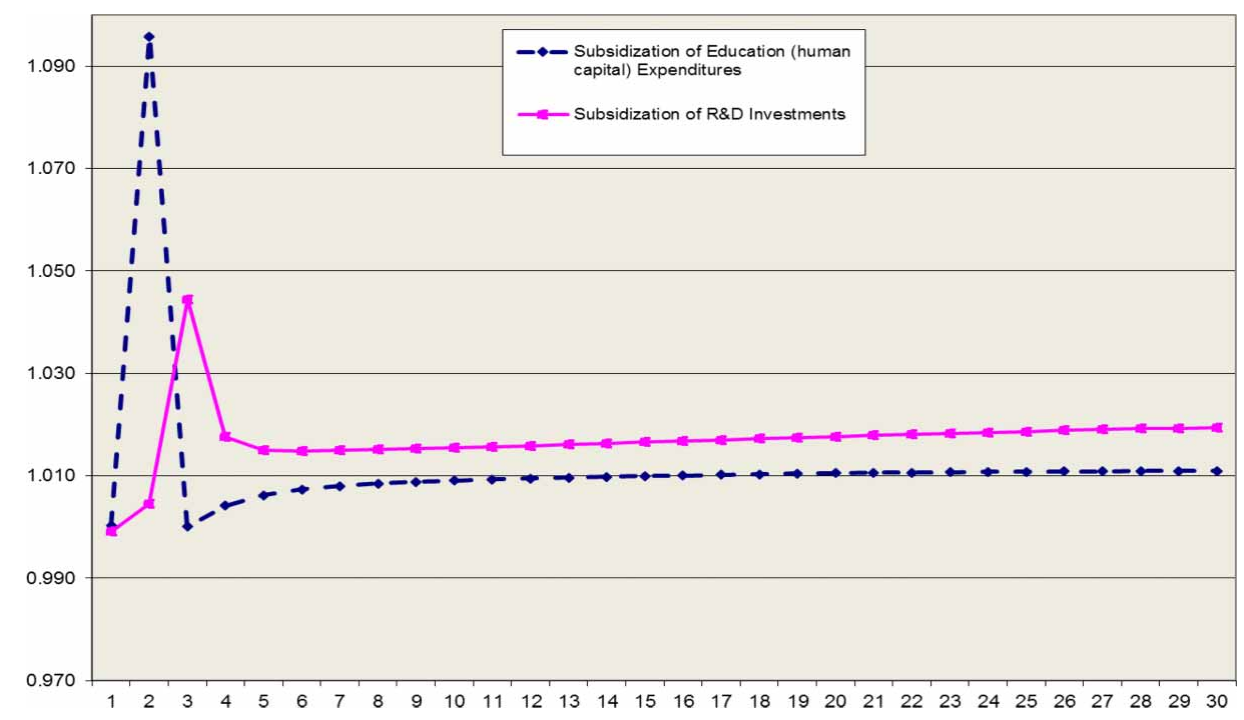

Figure 5. GDP under alternative subsidization programs (as a ratio to the base-path).

human capital by education activities through the income transfer leads to lower levels of human capital in R\&D and final good production sectors. As a result of this, once the initial stimulus wanes, production falls abruptly below the base-path as the economy faces a severe re-adjustment of balancing out the returns to human capital across its three uses (final good production, R\&D activities, and further human capital production). According to the model solutions, the initial gain in GDP is around $8 \%$. After this initial gain, as human capital has been re-allocated away from the R\&D and final good production, we witness the rapid scaling down of production activity. Over the medium to long run, more human capital formation eventually re-invigorates $R \& D$ activities. As the number of researchers expand in the R\&D sector, the economy starts to pick up through the expansion of capital varieties, and hence, of the level of final output. Over the long run, the equilibrium level of GDP lies about $1 \%$ above that of the base-path.

In contrast, the government subsidy on $R \& D$ investments has a relatively modest initial impact on GDP. GDP jumps by $4.5 \%$ upon impact, and then stabilizes around a plateau that is $2 \%$ higher than the base-path.

Overall, we observe that the growth paths display a fluctuating structure toward equilibrium. Revelation of such fluctuating structures toward equilibrium is recognized also in the comparable literature by Sequeira (2011) and Voyvoda and Yeldan (2011). In general, human capital employed by R\&D activities displays a more fluctuated structure than human capital employed by final good production. This result is an indicator of the trade-off impact of the most needed human capital in the economy.

Various relevant macro variables are portrayed in Figures 6-9. In Figure 6, we follow the equilibrium stock of knowledge capital (stock of R\&D, i.e. $A$ ). Subsidization of the R\&D investment activities leads to the expansion of the R\&D stock 4\% above the base-path. The R\&D subsidy ultimately leads to the expansion of the capital stock of the economy by increasing the number of differentiated capital 


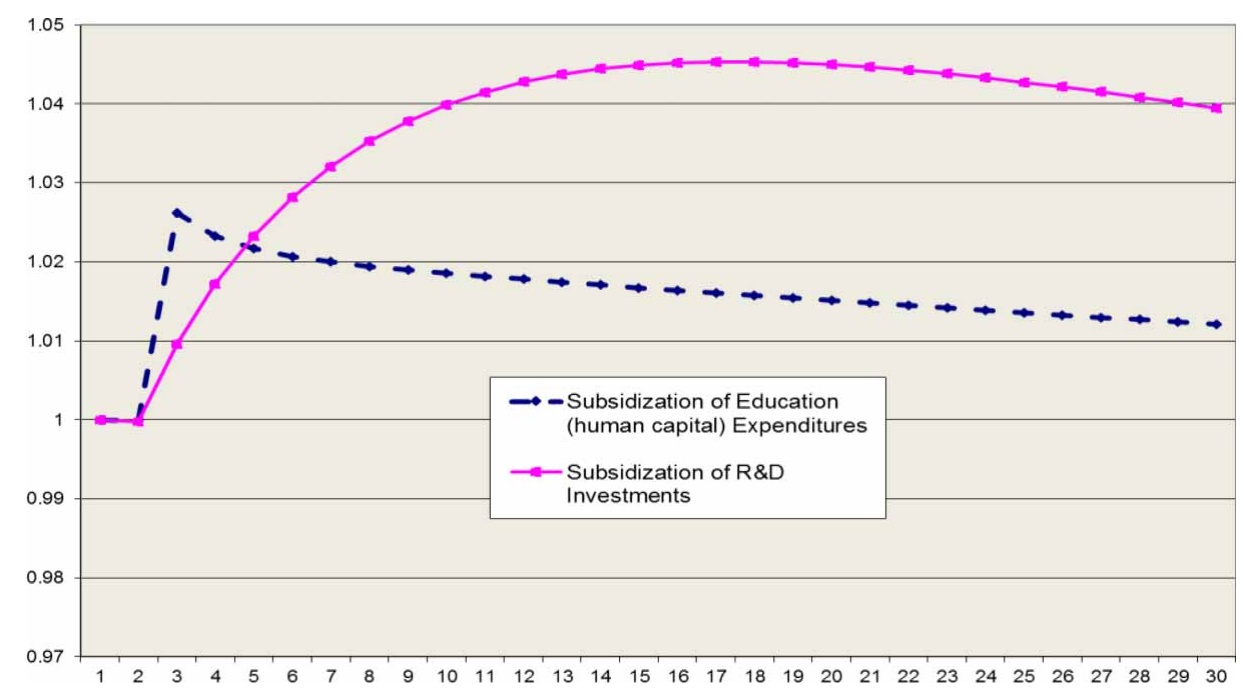

Figure 6. Stock of R\&D under alternative subsidization programs (as a ratio to the base-path).

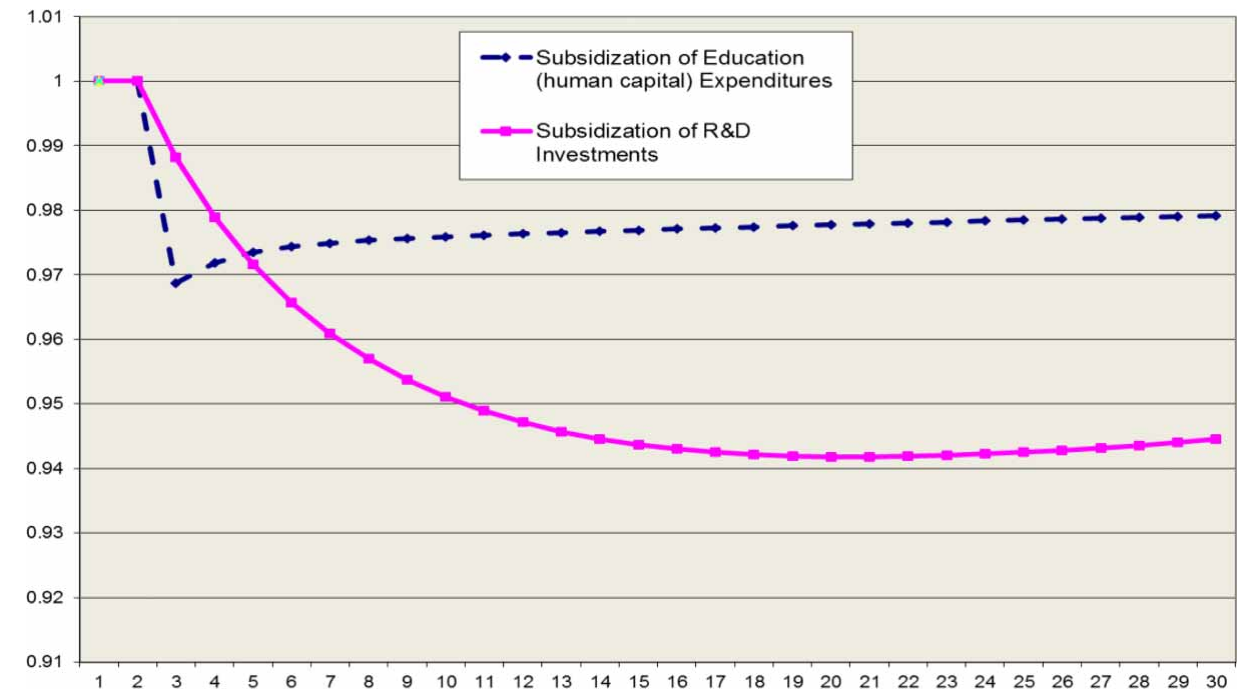

Figure 7. Stock of human capital under alternative subsidization programs (as a ratio to the base-path).

varieties. The education subsidy in the model is represented by a direct transfer of income from the government budget to the human capital accumulation activity. Announcement of the subsidy to human capital accumulation activity basically drives resources away from the R\&D activity, leaving the amount allocated to final goods sector only slightly lower. As a result, the accumulation of human capital in the economy continues at a higher pace than the accumulation of R\&D (Figure 7). Output growth, which is dependent on both the accumulation of R\&D and the human capital allocated to the final goods sector, is adversely affected due to this 
reason, as discussed above. Although the rate of growth of GDP quickly bounces back, the immediate negative effect of bidding resources away from the other sectors of the economy is felt during a longer transition period.

The announcement of an R\&D subsidy as reflected in the reduction of cost of inputs (wage costs of human capital, $w^{H}$ ) employed by the producers of $\mathrm{R} \& \mathrm{D}$, on the other hand, encourages them to pull primary resources away from other sectors. Under such an instrument, the demand for R\&D activities is increased to a higher steady-state level compared to the benchmark and the education subsidy scenario. On the other hand, total human capital built up is only slightly lower $(2.2 \%)$ with respect to the benchmark base-path; and the R\&D subsidy leads to the reallocation of the human capital stock at a rate of 3.5\% lower with respect to the education subsidy scenario. As more human capital is devoted to R\&D activities through subsidization, less is devoted to education, leading to an adjustment toward education activities in the following period. Such effects on total R\&D and total human capital stock of the economy are visible in Figure 7.

When the R\&D production cost is reduced by the subsidy, the stream of monopoly rents, acquired from the property rights of the blueprint increases. Such an increase stimulates further incentives for the production of capital, as new firms are attracted by increased profits. So, the subsidy to the cost of R\&D production encourages an upward shift in the demand for differentiated capital (new information technologies) production sector, leading to higher investment and higher capital accumulation in the economy, both during transition and at the steady state (Figure 8). It is basically the stimulation of the activity in the final goods sector that keeps both the wage rate of human capital and the price of R\&D higher under this scenario.

Another interesting result obtained from these observations is related to the pricing of human capital. The rapid increase in human capital stock under the government subsidy brings along a cheapening of the wage costs of human capital in the long

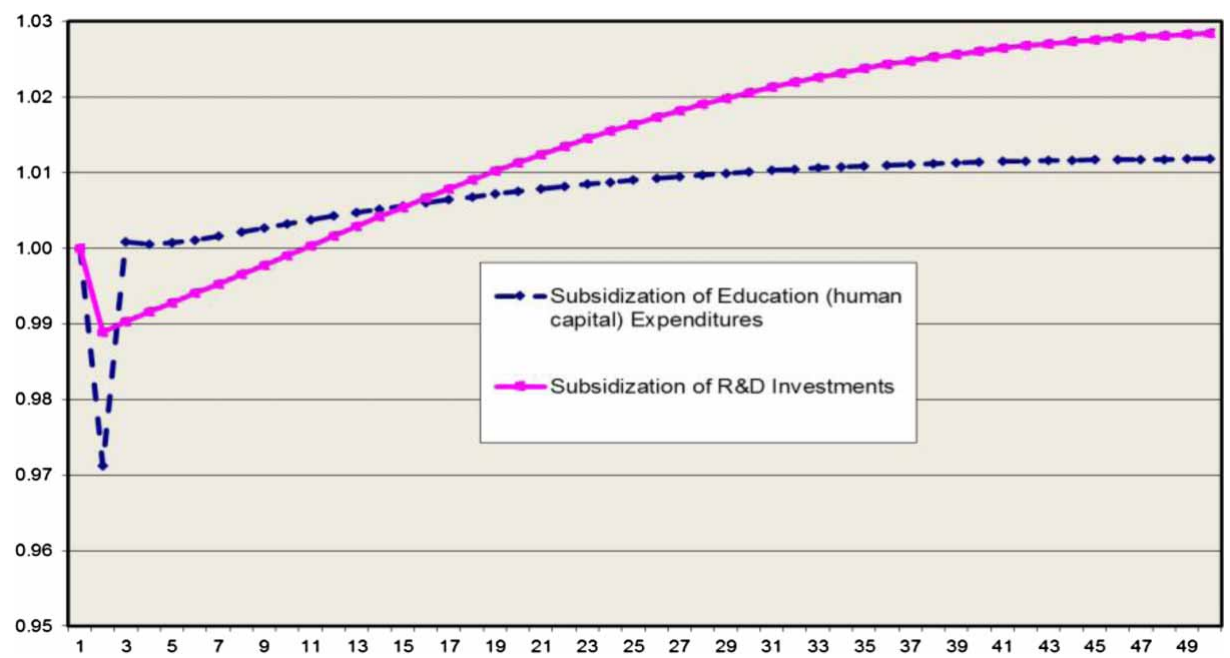

Figure 8. Differentiated capital varieties under alternative subsidization programs (as a ratio to the base-path). 


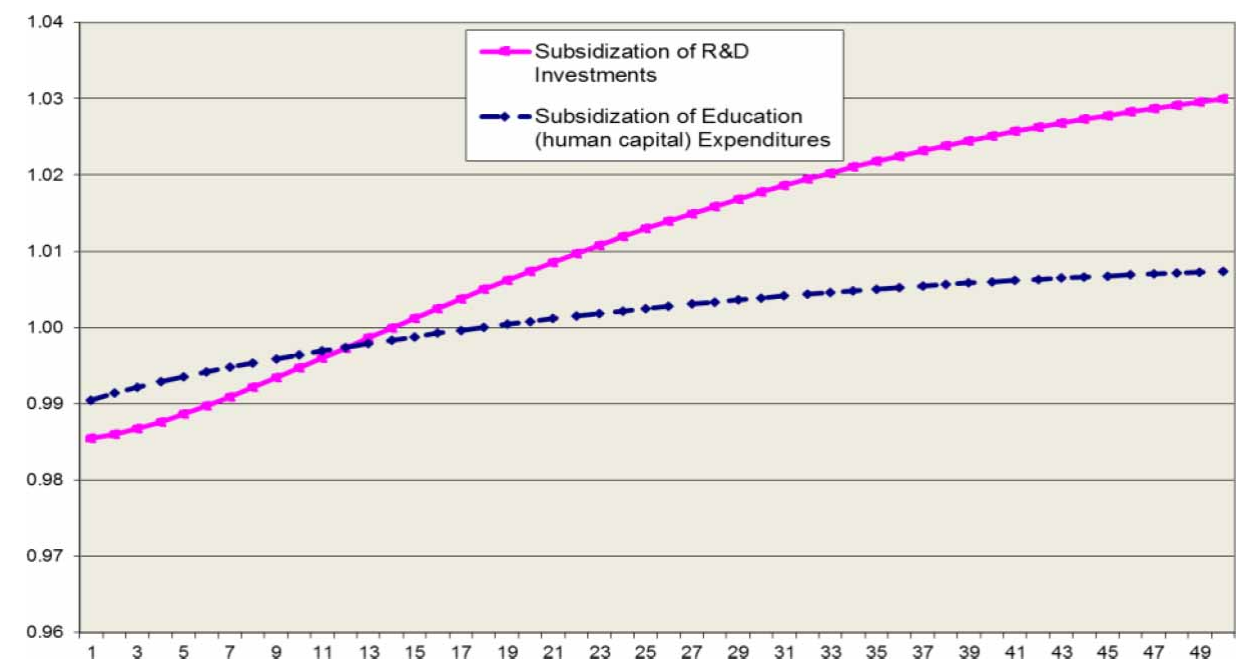

Figure 9. Wage rate of human capital under alternative subsidization programs (as a ratio to the base-path).

run. As one can observe from Figure 9, as a result of the direct subsidy to education, wage costs of human capital rise initially. But after this momentary reaction, the effect of the increased demand for human capital relative to supply leads to an increase in the wage rate, and thus, the wage rate of human capital catches up to its benchmark value by the 16 th period.

Within the R\&D subsidy system, the production process of human capital follows a different path. Subsidizing R\&D affects human capital wages in a milder but continuously positive manner. From the viewpoint of the algebraic structure of the model, as investment costs fall, a higher level of capital stock becomes available to the national economy. Such an augmentation directly influences the quantity of final good production and the factor incomes. Since, both profits generated by differentiated capital good production and wages are part of individuals' income, a direct government subsidy that channels resources to final good production provides conducive conditions in terms of long-run equilibrium dynamics. Lower levels of saving make room for the rise of expenditures. In other words, despite the low saving ratios, higher levels of production and consumption levels can be reached by means of government subsidization.

\section{Overview of results and concluding comments}

In this paper, we attempted to analytically investigate and assess the interactions between knowledge-driven growth, acquisition of human capital, and the role of strategic public policy for the Turkish economy within the context of a general equilibrium model. The model aims to investigate the public policies toward fostering the development of human capital (such as investments in education and learning) and those aimed at enhancing TFP through investments in physical capital and innovation (such as subsidies to R\&D). The main analytical rationale of the model rested on the complementary relationships between government expenditures on education and other knowledge capital investment, and private expenditures on R\&D and 
knowledge capital investment with a direct intent to provide a decomposition of growth dynamics for the Turkish economy.

In line with this scope, the algebraic structure of the model relies on the analytical set up of two main approaches: human capital-driven growth due to Lucas (1988), and R\&D-driven growth a la Romer (1990). Each analytical approach links growth to different elements individually and beyond that build economic activities through a representative consumer within the context of an abstract economy. The model used here by contrast aims to examine Turkey as a developing country by preserving its distinctive characteristics by using real data.

Formally, our policy question has been the following: for a government constrained by its budgetary requirements, which type of public subsidization policies are more conducive for enhancing growth and social welfare: promotion of human capital formation through subsidies to education expenditures, or promotion of new $R \& D$ formation through subsidies to $R \& D$ investment expenditures? To seek answers to this question, we first studied subsidization of education expenditures (subsidy on the buildup of human capital through skill-accumulation) and contrasted it with subsidization of the $R \& D$ activities (subsidy on the input costs to $\mathrm{R} \& \mathrm{D}$ ). The first policy experiment was designed to analyze the households' response in allocating human capital among different sectors and activities in the economy under conditions of increased rewards to education activities. The other policy instrument analyzed was designed to promote R\&D activities through a demand stimulus. This was implemented through the addition of an ad valorem subsidy to the input cost of the production of new $\mathrm{R} \& \mathrm{D}$.

Using the solutions of the model, one can derive the following summary conclusions:

- Stimulation policies of government on human capital and R\&D have permanent long-run consequences. This result documents that predictions of traditional neoclassical macroeconomic theories, which claim that government intervention can have only limited short-run impacts on the national economy with almost zero net effects in the long run, are not valid. Knowledge and education externalities serve as powerful tools to eliminate bottlenecks and market imperfections, and providing a second best equilibrium solution.

- The strategy of stimulating education expenditures by government subsidies initially induces positive influences on national income; however, in the long run, this positive impact fades away. As a result of stimulation of the education expenditures by government subsidization, national resources move away from other sectors (including R\&D sector), and are devoted to human capital accumulation. Relative contraction of the available R\&D sources cancel out the expected positive acceleration from human capital formation and leads to deceleration in GDP. But, blueprints/knowledge/contributions to technology created by R\&D generates direct benefits on capital variety expansion. For this reason, after the initial relative deceleration in $R \& D$ that downgrades capital accumulation and the rate of growth, long-run accumulation of human capital ultimately accelerates R\&D activity. As a result of these intertemporal reallocation adjustments, along with the sufficient increase in the number of R\&D researchers, R\&D production rises again and accelerates economic growth.

- As a consequence, the most important finding of the model is the determination of weakening of the positive impacts of a public stimulation program that is 
based on the stimulation of only education investment in the medium to long run. A single-handed strategy of only subsidizing education expenditures to promote human capital formation falls short of achieving desirable growth performance in the medium to long run. Under these observations, targeting a hybrid program, that stimulates education in the short-medium run and that promotes R\&D investments in the medium to long run, seems to be more appropriate for a government as a resource subsidization strategy.

As a final reminder for the reader, one should also be cautioned that, as in all quantitative modeling studies used in the social sciences, the obtained policy implications are sensitive to algebraic properties of the model in use. The applied general equilibrium model is a technical laboratory equipment which reflects a well-defined and harmonious general equilibrium system without any rigidities and/or structural imbalances on consumer and producer optimization basis. Thus, adjustments of the model economy to various policy shocks should not be seen as a criterion for real economies' global stability characteristics, but rather should be considered as a direct consequence of laboratory characteristics of a macroeconomic simulation apparatus. For these reasons, our results should be acknowledged as rough approximations of long-run equilibrium impacts of public stimulation and investment policies on production, employment, and physical and human capital accumulation, and consumer welfare. It is essential to continuously improve these policy suggestions obtained from such a social laboratory environment at this mathematical abstraction level with a more realistic and detailed analysis of national economies. We believe that the general equilibrium approach used in this study, that has the privilege of serving as a first attempt for the Turkish economy, is an important step toward this direction.

\section{Acknowledgements}

We also acknowledge our gratitude to the two anonymous referees of the $M E D J$ for their diligent guidance and comments on the earlier versions of the text. We are also grateful to Ibrahim Elbadawi, Çağrı Saglam, and to session participants at ERF 18th Annual Conference for their most valuable suggestions and comments. We also gratefully acknowledge our thanks to Filiz Özge Yağcıbaşı and Güneş Kolsuz for their very able research assistance. Needless to further mentioning, all remaining errors and views expressed remain as solely our responsibility.

\section{Disclosure statement}

No potential conflict of interest was reported by the author.

\section{Funding}

We gratefully acknowledge the research grant by The Scientific and Technological Research Council of Turkey (TÜBITAK, Grant No. 110K057) and the support of the Economic Research Forum (ERF).

\section{Notes}

1. This specification, rather than the more general form $A_{t+1}-A_{t}=\varphi H_{t}^{A} A_{t}$ as in Romer (1990), where the R\&D production function admits positive externalities through past research, helps to ensure the steady state. 
2. Total government tax revenues are composed of income tax, consumption tax, production tax, and tariff revenues.

3. As in static applied general equilibrium models, where calibration is based on the assumption that data reflect an economy in equilibrium, we assume that the benchmark data depict an initial steady-state growth path. This steady-state assumption for the benchmark data is widely used in applied intertemporal general equilibrium models. See, for example, Devarajan and Go (1998) for an empirical assessment.

\section{References}

Agénor, P.-R., Tarp-Jensen, H., Verghis, M., \& Yeldan, A. E. (2007). Disinflation, fiscal sustainability, and labor market adjustment in Turkey. In P. Agénor, A. Izquierdo, \& H. Tarp-Jensen (Eds.), Adjustment policies, poverty and unemployment: The IMMPA framework (pp. 383-456). Oxford: Basil Blackwell.

Aghion, P., \& Howitt, P. (1998). Endogenous growth theory. Cambridge: The MIT Press.

Altug, S., Filiztekin, A. \& Pamuk, V. S. (2008). Sources of long-term economic growth for Turkey, 1880-2005. European Review of Economic History, 12(3), 393-430.

Arrow, K. J. (1962). The economic implications of learning by doing. The Review of Economic Studies, 29(June), 155-173.

Dervis, K., deMelo, J., \& Robinson, S. (1982). General equilibrium models for development policy. London: Cambridge University Press.

Devarajan, S., \& Go, D. (1998). The simplest dynamic general-equilibrium model of an open economy. Journal of Policy Modeling, 20(6), 677-714.

Diao, X., Roe, T., \& Yeldan, E. (1999, March). How fiscal mismanagement may impede trade reform: Lessons from an intertemporal, multi-sector general equilibrium model for Turkey. The Developing Economies, 37(1), 59-88.

Filiztekin, A. (2001). Openness and productivity growth in Turkish manufacturing. Sabanc1 University, Discussion Paper Series in Economics No 2001-4.

Funke, M., \& Strulik, H. (2000). On endogenous growth with physical capital, human capital and product variety. European Economic Review, 44, 491-515.

Grossman, G. M., \& Helpman, E. (1991). Innovation and growth in the global economy. Cambridge: The MIT Press.

Grossman, G. M., \& Helpman, E. (1994). Endogenous innovation in the theory of growth. Journal of Economic Perspectives, 8, 23-44.

Hall, R. E. (1988). Intertemporal substitution in consumption. Journal of Political Economy, 96 (2), 339-357.

Jones, L. E., \& Manuelli, R. E. (1990). A convex model of equilibrium growth: Theory and policy implications. Journal of Political Economy, 98(5), 1008-1038.

King, R. G., \& Rebelo, S. T. (1993). Transitional dynamics and economic growth in the neoclassical model. American Economic Review, 83(4), 908-931.

Lewis, J. (1992). Financial repression and liberalization in a general equilibrium model with financial markets. Journal of Policy Modeling, 14(2), 135-166.

Lucas, R. E. (1988). On the mechanics of economic development. Journal of Monetary Economics, 22, 3-42.

OECD (2013a). Education at a glance. Paris: Author.

OECD (2013b). Main science and technology indicators. Paris: Author.

Öz, S. (2012, August). Middle income trap. Economic Research Forum, Policy Note, No 12-06.

Özsan, M., Taşci, K., \& Akpinar, R. (2011). Metropoliten Bölgelerin Rekabet Gücünü Etkileyen Faktörlere Teorik Bir Bakış. Akademik Bakış Dergisi, 12, 12-28.

Rebelo, S. T. (1991). Long-run policy analysis and long-run growth. Journal of Political Economy, 99(3), 500-521.

Romer, P. M. (1990). Endogenous technological change. Journal of Political Economy, 98(5), S71-S102.

Romer, P. M. (1992). Two strategies for economic development: Using ideas and producing ideas. Proceedings of the World Bank Annual Conference on development economics, IBRD, Washington, DC, 63-92. 
Sequeira, T. N. (2010). On the effects of human capital and R\&D policies in an endogenous growth model. Economic Modelling, 25, 968-982.

Sequeira, T. N. (2011). R\&D spillovers in an endogenous growth model with physical capital, human capital and varieties. Macroeconomic Dynamics, 15, 223-239.

Solow, R. (1956). A contribution to the theory of economic growth. The Quarterly Journal of Economics, 70, 65-94.

State Planning Organization (Ministry of Development) (2011). Annual Program, 2011, Ankara.

Stiglitz, J. E., \& Uy, M. (1996). Financial markets, public policy, and the East Asian miracle. The World Bank Research Observer, 11(2), 249-276.

Taymaz, E., Voyvoda, E., \& Yılmaz, K. (2008). Türkiye Imalat sanayinde Yapısal Dönüsüm, Üretkenlik ve Teknolojik Değişme Dinamikleri. METU ERC Working Papers in Economics, No 08/04.

Turkish Statistical Institute (Turkstat) (2008). Innovation Survey, 2006-2008. Ankara: Turkstat. TÜSİAD (2011). Türkiye'de Büyümenin klsitlart: Bir Önceliklendirme Çalışmast. Istanbul: Tüsiad Yay.

Voyvoda, E., \& Yeldan, A. E. (2005). Managing Turkish debt: An OLG investigation of the IMF's fiscal programming model for Turkey. Journal of Policy Modeling, 27(6), 743-765.

Voyvoda, E., \& Yeldan, E. (2011). Public policy and growth in Canada: An applied endogenous growth model with human and knowledge capital accumulation. Project Report prepared for Human Resources and Skills Development Canada, mimeo.

Yeldan, A. E. (1997). Financial liberalization and fiscal repression in Turkey: Policy analysis in a CGE model with financial markets. Journal of Policy Modeling, 19(1), 79-117.

Yeldan, A. E. (1998). On structural sources of the 1994 Turkish crisis: A CGE modeling analysis. The International Review of Applied Economics, 12(3), 397-414.

Yeldan, A. E., \& Güneş, K. (2014). 1980-Sonrası Türkiye Ekonomisinde Büyümenin Kaynaklarının Ayrıştırılması. Çalışma ve Toplum, 40(1), 49-66.

Yeldan, A. E., Taşçı, K., Voyvoda, E., \& Özsan, E. (2013, March). Escape from the middle income trap: Which Turkey? Report Prepared for TURKONFED, Istanbul.

\section{Appendix. The data and the calibration strategy}

\section{Calibration steps}

The data related to the initial period's equilibrium are drawn primarily from TurkStat inputoutput data set 2002 for Turkey. As the TurkStat data are originally in the form of annual flow values and primarily compiled for the purpose of static general equilibrium analyses, they need to be further augmented by information associated with the Turkish growth path, namely capital stock, technological knowledge stock, R\&D expenditures, growth rate(s), interest rate, and the discount rate in the intertemporal utility functional.

The intertemporal elasticity of substitution, $1 / \sigma$, in the household utility function is chosen in the range estimated by Hall (1988). The rate of time preference, $\rho$, is taken from Lucas (1988). The average growth rate between 1990 and 2005 for Turkey is chosen as the growth rate of human capital formation, hence for R\&D thereby, as the initial steady-state growth rate, $g_{A}(0)$, for the economy. The initial interest rate, $r_{0}$, then has to be calculated in a way consistent with the choices of $\sigma, \rho$, and $g_{A}(0)$. (see note 3 ). We further assume that the depreciation rate of capital varieties is zero.

The data on Turkish professional personnel occupation categories are used to adjust the original TurkStat data for the labor inputs. We distinguish the returns to the differentiated capital from the returns to the labor resource based on these data. This is accomplished using the calibration restrictions implied by the model. For purposes of calibration, we normalize the initial stock of the R\&D output $\left(A_{0}\right)$ to one. Then, the number of the new blueprints produced in the benchmark is equal to the growth rate, as $g^{A}(0)=\Delta A_{0} / A_{0}$.

To ensure the existence of a balanced growth path, we calibrate $\alpha_{k}$ and the total investment, including the value of $\mathrm{R} \& \mathrm{D}$ output $P^{A} \cdot \Delta A_{0}$, and the cost of new capital variety production $\mathrm{R} \& \mathrm{D}$, simultaneously see Equations (22), (25), and (27). 
Under the steady state, we know that $r_{S S}=g^{P^{A}}+\left(\Pi_{S S} / P^{A}\right)$. Now, recall the GDP identity from Equation (27):

$$
P^{Y} Y+P^{A} \Delta A=w^{L} L^{Y}+w^{H}\left(H^{Y}+H^{A}\right)+\frac{\prod}{\left(1-\alpha_{k}\right)} .
$$

Using the no-arbitrage equation, we have $\left(1+g^{P^{A}}(t)\right)=\left(1+r_{t+1} / 1+\left(\prod_{t+1} / P A_{t+1}\right)\right)$. Thus, under the steady-state equilibrium, the national income identity satisfies

$$
\mathrm{GDP}=w^{L} L^{Y}+w^{H}\left(H^{Y}+H^{A}\right)+\frac{P^{A}}{\left(1-\alpha_{k}\right)}\left(\frac{1+r}{1+g^{P^{A}}}-1\right)
$$

or equivalently,

$$
\left(1-\alpha_{k}\right)\left[\mathrm{GDP}-w^{L} L^{Y}-w^{H}\left(H^{Y}+H^{A}\right)\right]=P^{A}\left(\frac{1+r}{1+g^{P^{A}}}-1\right) .
$$

Using Equations (26) and (30) together,

$$
\left(1-\alpha_{k}\right) \alpha_{k}\left[\mathrm{GDP}-P^{A} \Delta A\right]=P^{A}\left(\frac{1+r}{1+g^{P^{A}}}-1\right) .
$$

Using the fact that $g_{P^{A}}$ and $g_{A}$ are related via Equation (29) in discrete time as $\left(1+g_{P^{A}}\right)=\left(1+g_{A}\right)^{\alpha_{H} /\left(1-\alpha_{k}\right)}$, and recalling that we had set $A_{0}=1$; using $\Delta A=g_{A}$, this information will allow us to utilize the following relationship for calibrating $P_{A}$ and $\alpha_{k}$ :

$$
\left(1-\alpha_{k}\right) \alpha_{k}\left[\mathrm{GDP}-g^{A} P^{A}\right]=P^{A}\left(\frac{1+r}{1+g^{P^{A}}}-1\right) .
$$

The second simultaneous relationship between $P_{A}$ and $\alpha_{k}$ is obtained from the savings investment equilibrium condition (22). Using Equations (22) and (25) together, and making note of the fact that $\Delta A / A=g_{A}$, we have

$$
\mathrm{SAV}=r \cdot \eta \cdot g^{A} \cdot k+r \cdot \eta \cdot \Delta k+P^{A} g^{A} .
$$

Since, from the optimal pricing rule of the monopolist (Equation 12) $r=\left(\alpha_{k} p_{k} / \eta\right)$, the saving - investment equilibrium can be re-written as

$$
\mathrm{SAV}=\frac{\alpha_{k}\left(g^{A}+g^{P^{A}}\right)}{r\left(1-\alpha_{k}\right)} \cdot P^{A}\left(\frac{1+r}{1+g^{P^{A}}}-1\right)+P^{A} g^{A}
$$

Now let us switch to calibration of the factor markets. We read the values of SAV, wages paid to human capital in the production of the final good, and the value added of $Y$ from data. Normalizing $w_{H}$ to unity, the share parameter $\alpha_{H}$ can be found as $\alpha_{H}=$ wages $H / Y$. And thus, $H_{Y}=$ wages $H$. We set the steady-state growth rate of $A$ to 0.015 . Then, using $\left(1+g_{P^{A}}\right)=\left(1+g_{A}\right)^{\left(\alpha_{H} / 1-\alpha_{k}\right)}$, we solve for $P_{A}$ and $\alpha_{k}$ via simultaneous iterations of Equations (32) and (33).

Using the F.O.C in the R\&D production function with $w_{H}=1$, we set $\varphi=1 / P_{A}$. Similarly, from the R\&D production function, $\Delta A=\varphi H_{A}$ with $A(0)=1$ and $g_{A}=0.025$; the level of human capital allocated to $\mathrm{R} \& \mathrm{D}$ is read as

$$
H_{A}(0)=\frac{g_{A}}{\phi}=g_{A} P_{A}
$$


For calibration, we set the initial values of $u_{A}, u_{H}$ and $u_{Y}$ to accordingly. Using the definition of $g_{A}$, this will allow us to solve for the level of aggregate human capital.

Using $H_{Y}$ from SAM data, $H_{A}(0)$ from Equation (34) and $H(0)$, we now calibrate for $H_{H}$ as

$$
H_{H}(0)=H(0)-H_{Y}(0)-H_{A}(0)
$$

Next, given $H(0)$, denote the calibration variable $\bar{z}=(H(0) / A(0))=H(0)$. From the rate of growth of $H$ Equation (20)

$$
\frac{\Delta H}{H}=g_{H}=g_{A}=\xi u_{H}+\left(\operatorname{sg}_{E}\right) \gamma\left(\frac{1}{\bar{z}}\right)^{1-\epsilon}
$$

We also have from the optimal $u_{Y}$ decision:

$$
u_{Y}=\frac{\xi \alpha_{H}}{\varphi\left(1-s^{H}\right)\left(1-\alpha_{k}\right) \alpha_{k}}\left(\frac{1}{\bar{z}}\right)-\frac{\epsilon \gamma \alpha_{H}}{\varphi\left(1-\alpha_{k}\right) \alpha_{k}} \bar{z}
$$

Equations (36) and (37) are iterated to solve for the parametric values of $\gamma$ and $\xi$.

Using discrete time, condition for equilibrium growth of consumption is

$$
\left(\frac{1+r_{\mathrm{SS}}}{1+\rho}\right)^{1 / \sigma}=1+g_{c} .
$$

Thus, the growth in final good becomes $g_{Y}=g_{C}$. The rest of the system is calibrated using standard methods of applied general equilibrium.

Table A1 presents the initial levels of selected variables and parameters obtained from sources other than the main data base or from this calibration process. The initial state of the macroeconomic equilibrium of the Turkish economy (2005).

Table A1. Pre-assumed and calibrated values of structural parameters.

Share of human capital in final good value added, $\alpha_{H}$

Share of plain labor in final good value added, $\alpha_{L}$

Share of rental value of differentiated capital in final good value added, $\alpha_{K}$

0.647

R\&D production productivity parameter, $\varphi$

Productivity of schooling in human capital formation, $\xi$

0.012

Productivity of learning via knowledge and varieties, $\gamma$

0.020

Share of past human capital in human capital formation, $\epsilon$

0.879

Value of input-output coefficient to produce unit capital variety, $\eta$

Share of human capital allocated to final good production, $H_{Y} / H$

0.158

Share of human capital allocated to R\&D production, $H_{A} / H$

Share of human capital allocated to human capital formation, $H_{H} / H$

Value of R\&D expenditures as a ratio to GDP, $P_{A} \Delta A / \mathrm{GDP}$

0.061

Ratio of aggregate savings to GDP, SAV/GDP

Share of oligopolistic profits in GDP, $\prod / G D P$

0.202

Inverse of intertemporal elasticity of substitution for the consumer, $\sigma \quad 1.0001$

$\begin{array}{ll}\text { Subjective discount rate, } \rho & 0.030\end{array}$

Income tax rate, $t_{y} \quad 0.032$

Armingtonian elasticity of substitution between $M$ and DC, $\varepsilon_{\mathrm{CC}} \quad 3.000$

CET elasticity of transformation between $E$ and DC, $\varepsilon_{\text {CET }}$ 